Marco A. M. Ortega

Laura B. Rodríguez
Cadernos Prolam/USP, v.16, n.31, p.160-188, jul./dez.2017

DOI: 10.11606/issn.1676-6288.prolam.2017.140636

\title{
LA SEGREGACIÓN RESIDENCIAL SOCIOECONÓMICA Y SU RELACIÓN CON LA DESIGUALDAD ECONÓMICA EN MÉXICO
}

\author{
THE SOCIOECONOMIC RESIDENTIAL SEGREGATION AND ITS RELATION \\ WITH THE ECONOMIC INEQUALITY IN MEXICO
}

\author{
SEGREGAÇÃO RESIDENCIAL SOCIOECONÓMICA E SUA RELAÇÃO \\ COM A DESIGUALDADE ECONÔMICA NO MÉXICO
}

Marco Antonio Medina Ortega ${ }^{1}$

Universidad de Guadalajara, Guadalajara, México.

Laura Elizabeth Benavides Rodríguez ${ }^{2}$ Instituto Tecnológico Mario Molina, Guadalajara, México.

Resumen: Actualmente existe una gran diversidad de perspectivas en las que se aborda el estudio de la ciudad, dentro de estas se destaca un creciente interés por los trabajos que analizan la ciudad desde el enfoque de la desigualdad social y la segregación urbana. En este documento se presentan algunas reflexiones contemporáneas respecto al tema de la segregación residencial socioeconómica (SRS); el recorrido se realiza desde los primeros antecedentes de estudios sobre la segregación con la finalidad de concretar un marco analítico base, para posteriormente entrar en materia con el fenómeno de la segregación en América Latina, así como identificar los estudios de relevancia y concretar un breve estado de la cuestión que se sintetizará en la construcción de dos líneas del tiempo una para América Latina y otra para México. Nuestra intención es que el presente artículo es una oportunidad para reflexionar sobre las diferencias y desigualdades socioeconómicas; y contribuir en el esclarecimiento de nuestra percepción sobre los otros grupos sociales que comparten con nosotros la jerárquica pirámide socioeconómica.

Palabras clave: Segregación residencial socioeconómica, América Latina, desigualdades sociales.

\footnotetext{
${ }^{1}$ Profesor-Investigador adscrito al Departamento de Estudios Regionales-INESER de la Universidad de Guadalajara, forma parte de la planta docente del Doctorado en Ciudad, Territorio y Sustentabilidad (CUAAD/UdeG), sus áreas de interés son economía urbana y reestructuración económica, email: mrmedina@cucea.udg.mx.

${ }^{2}$ Estudiante del doctorado en Ciudad, Territorio y Sustentabilidad (CUAAD/UdeG). Profesor adscrito a la División de Arquitectura del Instituto Tecnológico Mario Molina (TecMM), sus áreas de interés son la sociología urbana y el urbanismo sustentable, email: laura.benavides@elgrullo.tecmm.edu.mx
} 
Marco A. M. Ortega

Laura B. Rodríguez
Cadernos Prolam/USP, v.16, n.31, p.160-188, jul./dez.2017

DOI: 10.11606/issn.1676-6288.prolam.2017.140636

Abstract: There exists a big diversity of perspectives in which the study of the city is tackled. In the last years there is observed an increasing interest in the works that analyze the city from the perspective of the social inequality and the urban segregation. In this document some contemporary reflections appear with regard to the topic of the socioeconomic residential segregation (SRS); the trip is realized from the first studies precedents on the segregation for the purpose of specifying a basic analytical frame, later to enter matter with the phenomenon of the segregation in Latin America, as well as to identify the relevancy studies and to specify the brief state of the question that will synthesize in the construction of two lines of the time one for Latin America and other one for Mexico. Nevertheless, our intention is that the present article is an opportunity to reflect on the differences and socioeconomic inequality; and concientizar the perception on other social groups who share with us the hierarchic socioeconomic pyramid.

Keywords: Socioeconomic residential segregation, Latin America, social inequalities.

Resumo: Existe uma grande diversidade de perspectivas nas quais o estudo da cidade é estudado. Nos anos passados é observado um interesse crescente nos trabalhos que analisam a cidade da perspectiva da desigualdade social e a segregação urbana. Neste documento algumas reflexões contemporâneas aparecem quanto ao tópico da segregação residencial socioeconômica (SRS); a análise é realizada dos primeiros precedentes de estudos na segregação para fins de especificar uma base analítica, para depois entrar na matéria com o fenômeno da segregação na América Latina, bem como identificar os estudos de pertinência e especificar o breve estado da pregunta, que sintetizará na construção de duas linhas do tempo uma para a América Latina e outra para o México. No entanto, a nossa intenção consiste em que o presente artigo é uma oportunidade de refletir sobre as diferenças e desigualdade socioeconômica; e busca concientizar a percepção em outros grupos sociais que compartilham conozco, a pirâmide socioeconômica hierárquica.

Palavras-chave: segregação residencial socioeconômica, a América Latina, desigualdade social.

\section{INTRODUCCIÓN}

El interés por el análisis del fenómeno de la segregación urbana tiene sentido cuando se subraya el aumento de la diferenciación y desigualdad social en las ciudades de América Latina y particularmente en México. Prácticamente, todas las áreas metropolitanas de nuestro país 
Marco A. M. Ortega

Laura B. Rodríguez
Cadernos Prolam/USP, v.16, n.31, p.160-188, jul./dez.2017

DOI: 10.11606/issn.1676-6288.prolam.2017.140636

presentan una clara división entre las áreas residenciales de alto nivel, las de clase media y las áreas donde habitan los grupos más pobres y desfavorecidos (GONZÁLEZ ARELLANO, 2011). Este proceso, es parte esencial del desarrollo actual de nuestras ciudades y se ha convertido en una importante línea de investigación en México.

Por lo tanto, este trabajo pretende mostrar la evolución de los estudios sobre el tema de la segregación urbana, abordando aspectos teórico-conceptuales y de tipo metodológico, para ser sintetizando en un breve estado de la cuestión y en la construcción de líneas del tiempo, clasificando sus principales aportaciones en cuestiones teóricas y/o metodológicas.

De acuerdo con Sabatini, Cáceres y Cerda (2001) la segregación residencial es un fenómeno espacial con complejas conexiones con las diferencias y desigualdades sociales, complejidad que suele conducir a confusión. Por ello, es importante precisar qué entendemos por segregación y qué dimensiones presenta el fenómeno; como punto inicial se plantea el término de segregación con una connotación de separación o aislamiento. El resultado de esta operación es la composición social de cada vecindario tiende a ser cada vez más homogénea al interior y más heterogénea entre barrios, reduciendo las oportunidades de interacción entre grupos sociales y con ellos la percepción de pertenecer a "mundos aislados" (SARAVÍ, 2008 pág. 1), al respecto Sabatini, señala que:

la segregación residencial corresponde a la aglomeración en el espacio de familias de una misma condición social, más allá de cómo definamos las diferencias sociales. Puede ser según condición étnica, origen migratorio, etaria o socioeconómica (2006 pág. 7).

Una de las primeras deducciones sobre el tema de la segregación es la profundidad de acción de los términos de "separados-diferentes", esta relación permutará pasando desde condiciones étnicas hasta cuestiones socioeconómicas. En el caso particular de México, esta relación de términos mantiene una fuerte relación con el poder económico; dejando una sensación de diferenciación, desigualdad y/o exclusión que ha penetrado en la percepción de la población mexicana y se evidencia espacialmente en nuestras ciudades.

\section{LOS ESTUDIOS SOBRE LA SEGREGACIÓN RESIDENCIAL}

La segregación urbana es un tema considerado como tradicional dentro de la sociología urbana, los primeros estudios son desde hace casi un siglo, y fueron realizados en EEUU, luego en Europa, y posteriormente en América Latina. Como disciplina científica surgió en el seno de 
Marco A. M. Ortega

Laura B. Rodríguez
Cadernos Prolam/USP, v.16, n.31, p.160-188, jul./dez.2017

DOI: 10.11606/issn.1676-6288.prolam.2017.140636

la escuela de Sociología de Chicago a principios del siglo XX, siendo la causa racial el motivo original de análisis. Actualmente diversas disciplinas abordan el tema de la segregación urbana, dando lugar a un análisis diverso del fenómeno, en ese sentido una de las principales pretensiones del trabajo es proponer una sistematización de los diversos trabajos y/o enfoques, a manera de un primer acercamiento, sin que ello signifique la intención de definir o elegir en este trabajo una perspectiva analítica, por supuesto que lo anterior no significa que dejemos de reconocer el sustancial aporte que la sociología urbana ha tenido al respecto de este tema de investigación hasta nuestros días.

Uno de los primeros exponentes desde la visión sociológica fue Robert E. Park quien en 1926 afirmaba que la distribución espacial de la población radicaba en que las distancias físicas podrían considerarse indicadores de distancias o diferencias sociales (1926). A partir de ese trabajo se destaca la necesidad de medir las relaciones de desigualdad presentes en el espacio urbano; a partir de 1940 surgen trabajos que proponen una serie de indicadores cuantitativos para medir la segregación residencial. Por lo tanto, cabe citar los estudios de Bell (1954), que introduce en un marco analítico instrumentos más complejos como los empleados en la llamada ecología factorial y denominados como índices de interacción; posteriormente encontramos el aporte de Duncan y Duncan (1955), que presentan su indice de segregación y disimulitud que permiten medir la distribución de un determinado grupo de población en el espacio urbano, siendo uno de los indicadores más utilizados para medir el fenómeno.

Por su parte, los sociólogos urbanos de la Universidad de California, conocidos como la Escuela de Los Ángeles, buscaron en la década de los 80 explicar las áreas sociales homogéneas identificables en el medio urbano. Esta escuela analiza los efectos socio-espaciales de la reestructuración económica, particularmente como consecuencia del post-fordismo y la globalización. Dentro de esta corriente los estudios elaborados por Massey y Denton (1988) dieron una nueva dimensión al análisis con su propuesta de índice espacial de segregación. Dicho índice permite clasificar y comparar la desigual distribución de la población teniendo en cuenta las particularidades de las zonas de cada ciudad, permitiendo así la comparación en el espacio y en el tiempo.

Otro aporte de los miembros de esta escuela fue el realizado por Michael J. White (1983), quien se ocupó de revisar y sistematizar las diferentes definiciones que en torno a la segregación existían en diferentes disciplinas. De acuerdo con este autor, en términos sociológicos la 
Marco A. M. Ortega

Laura B. Rodríguez
Cadernos Prolam/USP, v.16, n.31, p.160-188, jul./dez.2017

DOI: 10.11606/issn.1676-6288.prolam.2017.140636

segregación se refiere a la ausencia de interacción entre grupos sociales y en sentido geográfico resaltaba la desigual distribución de los grupos sociales en un espacio físico determinado.

\section{ESTUDIOS EN AMÉRICA LATINA}

Los primeros acercamientos al fenómeno en América Latina fueron los aportes de Peter Amato (1970) sobre el papel de las élites en la reorganización de los patrones tradicionales del uso del suelo y en el desarrollo de nuevas configuraciones de asentamiento. Posteriormente, Paul Van Lindert y Otto Verkoren (1982) publican el artículo "Segregación residencial y política urbana en La Paz, Bolivia", texto que aborda el crecimiento y distribución de la población de la ciudad de La Paz con base en políticas urbanas de efecto segregador.

Francisco Sabatini (1982) realiza su primera publicación sobre el tema de la segregación urbana, un artículo que lleva por nombre "Santiago, sistemas de producción de vivienda, renta del suelo y segregación urbana:1970-1980" y posteriormente, Armando de Ramón (1992), publica el libro "Santiago de Chile: 1541-1991, Historia de una sociedad urbana", a través de un recorrido histórico expresa el fenómeno de la segregación en la ciudad. Durante la década de los 90, se realizan los primeros escritos sobre las urbanizaciones cerradas, como modelos urbanos que manifiestan explícitamente la segregación social y fragmentación urbana. Los primeros documentos que describen la segregación se realizan en Argentina, la ciudad de Buenos Aires es una de las primeras urbes estudiadas sobre el fenómeno, sobresaliendo las investigaciones de Svampa (2001), quien planteó la ciudad como un campo de crecimiento del proceso de segregación espacial expresado en el explosivo aumento de los fraccionamientos cerrados y countries privados.

Por su parte la socióloga Teresa Caldeira, en su libro "Ciudad de Muros: crimen, segregación y ciudadanía en Sao Paulo" (2000) expresa que la ciudad de San Paulo es una de las ciudades con la más inequitativa distribución de la riqueza en el mundo, argumenta que los denominados enclaves fortificados, ha tenido como consecuencia un nuevo modelo de segregación espacial que no solo transforma la vida pública, sino que además se consideran como fuente de estatus y diferenciación social.

En seguida, se abordan una serie de debates académicos que dimensionan la importancia del estudio sobre el tema; dentro de estos, sobresale el Seminario Internacional de Segregación en la 
Marco A. M. Ortega

Laura B. Rodríguez
Cadernos Prolam/USP, v.16, n.31, p.160-188, jul./dez.2017

DOI: 10.11606/issn.1676-6288.prolam.2017.140636

Ciudad (Smolka, y otros), organizado por el Instituto Lincoln de Políticas de Suelo -LILP- en el año 2001; otro fue el Coloquio Latinoamérica: Países Abiertos, Ciudades Cerradas (CABRALES BARAJAS, 2002), organizado por el Departamento de Geografía de la Universidad de Guadalajara en 2002, y posteriormente el curso-seminario "Segregación Social del Espacio: nuevos enfoques y patrones emergentes en México y Chile" (CABRALES BARAJAS, 2006), patrocinado por la Universidad Nacional Autónoma de México en 2006.

A partir de las primeras décadas del siglo XXI se han realizado importantes investigaciones al respecto de la segregación urbana, entre sus aportes encontramos: i) conceptualizan el fenómeno en la realidad de América Latina, ii) identifican las principales modalidades de segregación y sus dimensiones, iii) explican los patrones tradicionales y el cambio hacia el nuevo modelo; iv) proponen metodologías y nuevas formas de cuantificar la segregación, al igual que escalas de valoración, y v) explican las causas y repercusiones del fenómeno.

Dentro de la perspectiva de la segregación urbana, el enfoque de la Segregación Residencial Socioeconómica (SRS) es el que nos interesa profundizar. En esta línea de pensamiento destacan autores cuyos trabajos proponen un conjunto de variables para explicar el fenómeno. Al respecto, destaca el análisis realizado por Jaramillo (2009) a través del estudio de las relaciones entre el uso y valor del suelo y su relación con la población que lo habita; al igual que las formas de acceso al suelo urbano por parte de la sociedad (ABRAMO, 2003). Existe otros trabajos que se centran en establecer el vínculo entre los trabajadores menos calificados en el mercado de trabajo y la creciente concentración de estos en barrios con alta densidad de pobreza (KATZMAN Y RETAMOSO 2005).

Existen otros trabajos que ven la SRS en una realidad en particular, son los realizados en las zonas metropolitanas de Santiago de Chile por Arriagada y Rodríguez Vignoli (2003) y Sabatini (2006); en las ciudades de Mexico, Guadalajara y Monterrey con los estudios puntuales y progresivos de Ruvalcaba y Schteingart (2012) y Gónzalez Arellano (2011) y la ciudad de Buenos Aires por Rodríguez Merkel (2014). Los estudios no solo abordan las grandes áreas metropolitanas, sino que se extienden a las ciudades medias, como la ciudad de Córdoba en Argentina, con los estudios de Molinatti (2013), Marengo y Elorza (2014); en ciudades turísticas como Puerto Vallarta con los trabajos de Baños Francia (2009) y Pérez Campuzano (2010), y otros abarcan países enteros como el caso de Argentina con los trabajos de Groisman (2009). 
Marco A. M. Ortega

Laura B. Rodríguez
Cadernos Prolam/USP, v.16, n.31, p.160-188, jul./dez.2017

DOI: 10.11606/issn.1676-6288.prolam.2017.140636

Después de este breve recorrido sobre los trabajos que analizan la SRS, se proponen tres esquemas que muestran una síntesis sobre las aportaciones realizadas por diversos autores al tema. Para comenzar el esquema 1, expone de forma sintetizada el avance de los estudios sobre el SRS en América Latina y establecer un breve Estado del Arte. Posteriormente, se añaden dos esquemas más, cuyo fin es mostrar algunas de las investigaciones sobre el tema en América Latina (esquema 2) y particularmente en México (esquema 3).

La representación se realiza a manera de línea de tiempo y abarca desde el comienzo del siglo XX a la actualidad. Esta herramienta permite una rápida visualización que evidencia las aportaciones realizadas y permite marcar la evolución de los estudios sobre la segregación desde diversas perspectivas, para comprender de manera rápida y concreta las aportaciones más recientes al fenómeno. Cada esquema muestra los trabajos clasificados en dos niveles, en la parte superior se colocaron aquellos estudios que principalmente presentan aportaciones teóricoconceptuales al tema de la segregación; en la parte inferior se localizan los estudios con aportaciones y aplicaciones metodológicas.

En la actualidad los estudios sobre la SRS tienden a analizar las diversas dimensiones del fenómeno y no solo se abordan a través de un enfoque cuantitativo, sino también se adentran en los aspectos cualitativos. Al respecto autores como Saraví (2008) señalan la imperiosa necesidad de considerar tanto las dimensiones "objetiva" (cuantitativa) y "subjetiva" (cualitativa) en el estudio sobre la segregación urbana, para esclarecer aspectos como los estigmas territoriales que presentan hoy en día las ciudades de América Latina. Para destacar esta cualidad, en cada una de las lineas del tiempo se especifica el tipo de investigación, señalando si es de tipo cualitativo o mixto. Por último, se agregan algunas tablas en un anexo al final del documento, referidas a la bibliografía considerada para la elaboración de cada línea del tiempo. 


\section{Esquema 1. Síntesis del Estado del Arte sobre la SRS en América Latina}

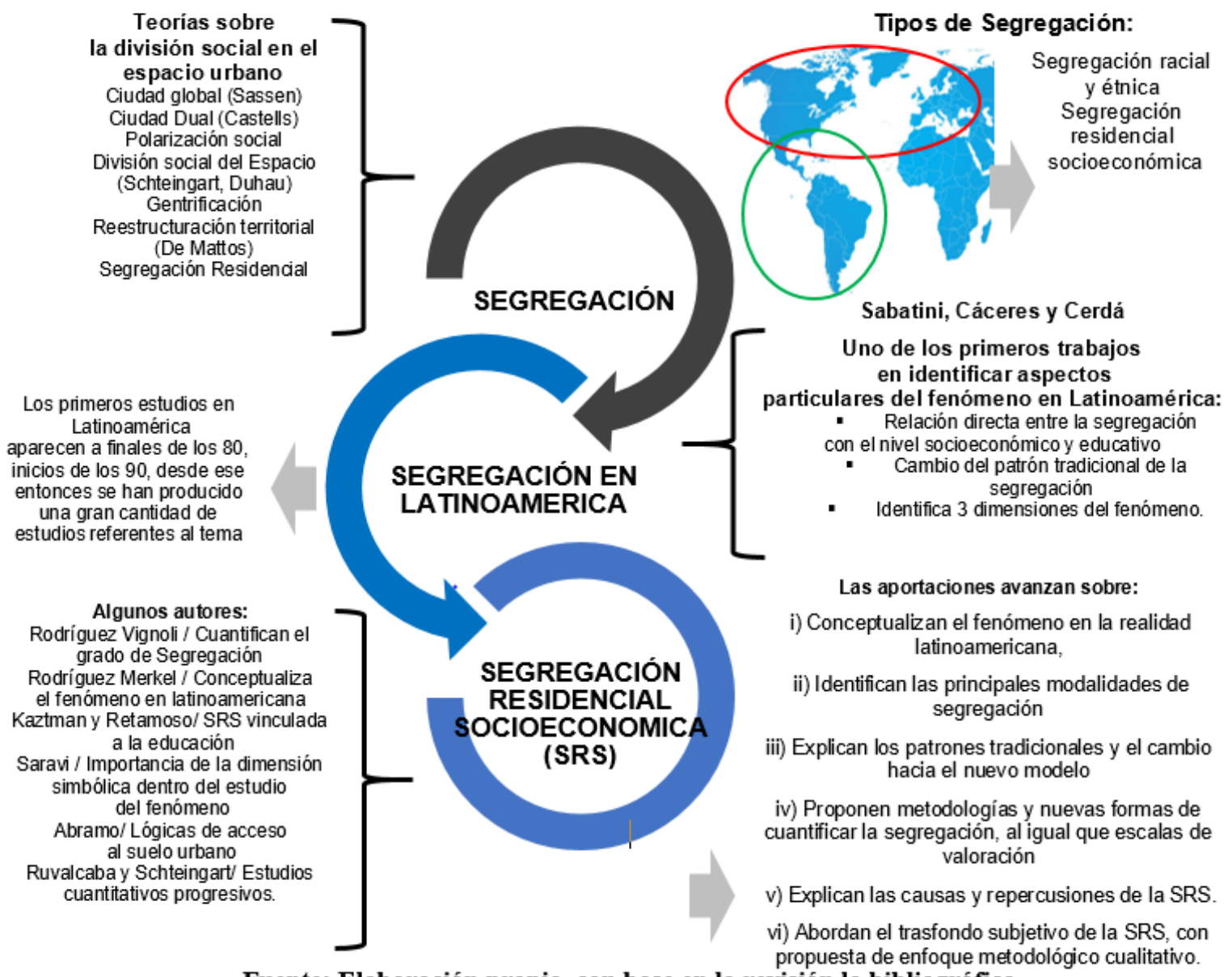

Fuente: Elaboración propia, con base en la revisión la bibliográfica 
Marco A. M. Ortega Laura B. Rodríguez
Cadernos Prolam/USP, v.16, n.31, p.160-188, jul./dez.2017

DOI: 10.11606/issn.1676-6288.prolam.2017.140636

Esquema 2. Línea de tiempo que aborda algunos de los estudios realizados sobre la SRS en América Latina desde principios del siglo XX

\begin{tabular}{|c|c|c|c|c|c|c|c|c|c|c|c|c|c|c|c|c|}
\hline Caldeira & $\begin{array}{l}\text { Prevot } \\
\text { Schapira Abramo }\end{array}$ & & Roitman & Svampa & & & & & & & & & Duhau & Molinatti & López Morales & \\
\hline  & 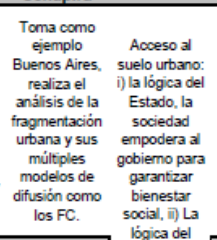 & & 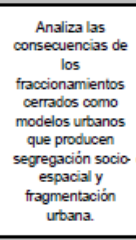 & $\begin{array}{l}\text { Consecuencias } \\
\text { sociologicas de las } \\
\text { urbanizaciones } \\
\text { cerradas. Este tpo } \\
\text { de modelo urbano } \\
\text { dinamizaz las } \\
\text { diferencias sociales } \\
\text { entre ganasores y } \\
\text { perdedores. }\end{array}$ & & & & & & & & &  & 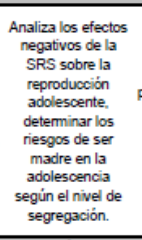 & 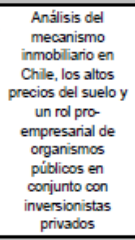 & \\
\hline Prevot Schapira & 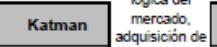 & & Sabatini & Saravi & $\begin{array}{l}\text { Tecco y } \\
\text { Fernández }\end{array}$ & $\begin{array}{l}\begin{array}{l}\text { Tecoooy } \\
\text { Váldez }\end{array} \\
\end{array}$ & $\begin{array}{l}\text { Brain y } \\
\text { Sabatini }\end{array}$ & Sabatini y Brain & & Marcos & & $\begin{array}{l}\text { Ruiz Table y } \\
\text { López }\end{array}$ & Linares & $\begin{array}{c}\text { Rodriguez } \\
\text { Merkel }\end{array}$ & Matossian & Marengo y Elorza \\
\hline 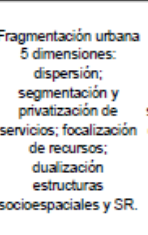 & 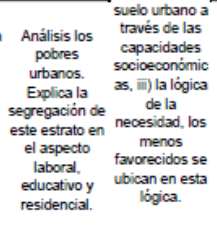 & &  & 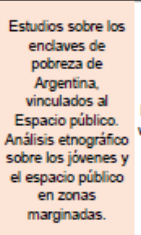 & $\begin{array}{l}\text { Efectos de la } \\
\text { segregación en } \\
\text { los programas de } \\
\text { viviendas sociales } \\
\text { en la Ciudad de } \\
\text { Córdoba. }\end{array}$ & $\begin{array}{l}\text { Estudio sobre la } \\
\text { SRS en la ciudad } \\
\text { de Córdoba. } \\
\text { Argentina, analiza } \\
\text { los efectos } \\
\text { negastivos y } \\
\text { sugieren politcas } \\
\text { que atenuar los } \\
\text { efectos negativos. }\end{array}$ & $\begin{array}{l}\text { Resaltan la } \\
\text { importancia de } \\
\text { disminuir la } \\
\text { segregación en } \\
\text { Amenencic Latina, } \\
\text { con propuestas } \\
\text { deste la poltica } \\
\text { pública, exponen } \\
\text { mitosy } \\
\text { caracteriticas de } \\
\text { la segregación. }\end{array}$ & 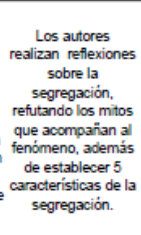 & & 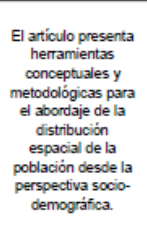 & & 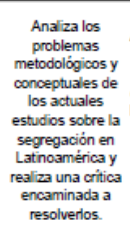 & 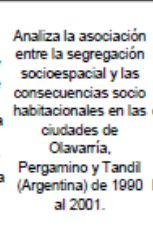 & $\begin{array}{l}\text { Define la sRS e } \\
\text { implicaciones, } \\
\text { estableciendo que } \\
\text { existe un grupo vue } \\
\text { es segregaso y un } \\
\text { grupo segregasor. } \\
\text { dejando a un lado } \\
\text { la autosegregación. }\end{array}$ & 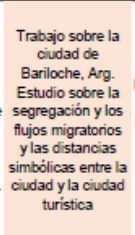 & 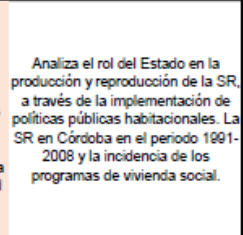 \\
\hline \multirow[t]{3}{*}{2000} & 2001 & 2002 & 2003 & 2004 & 2005 & 2006 & 2007 & 2008 & 2009 & 2010 & 2011 & 2012 & 2013 & 2014 & 2015 & 2016 \\
\hline & \multicolumn{16}{|c|}{ Aportaciones metodológicas o aplicación de metodologia } \\
\hline & $\begin{array}{c}\text { Sabatini, Cáceres y } \\
\text { Cerda }\end{array}$ & $\begin{array}{l}\text { Katman y } \\
\text { Wormald }\end{array}$ & $\begin{array}{c}\text { Rodrinuezy } \\
\text { Ariagazal }\end{array}$ & $\begin{array}{c}\text { Rodriguez y } \\
\text { Arriagada } \\
\end{array}$ & $\begin{array}{c}\text { Katman, } \\
\text { Retamoso } \\
\end{array}$ & $\begin{array}{l}\text { Katman, } \\
\text { Retamoso } \\
\end{array}$ & $\begin{array}{l}\text { Katman, } \\
\text { Retamoso } \\
\end{array}$ & $\begin{array}{c}\begin{array}{c}\text { Rodriguez } \\
\text { Vignoli }\end{array} \\
\end{array}$ & Flores, Sabatini & $\begin{array}{c}\text { Aliagana y } \\
\text { Alvarez } \\
\end{array}$ & Groisman & $\begin{array}{c}\begin{array}{c}\text { Rodriguez } \\
\text { Merkel }\end{array} \\
\end{array}$ & Molinatti & $\begin{array}{l}\text { Marango, } \\
\text { Elorza }\end{array}$ & & $\begin{array}{c}\begin{array}{c}\text { Rodriguez } \\
\text { Merkel }\end{array} \\
\end{array}$ \\
\hline & 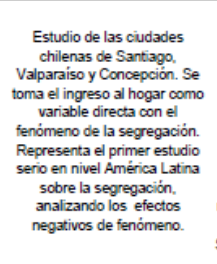 & \multirow{2}{*}{ 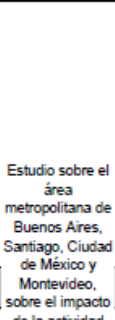 } &  & 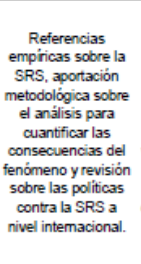 & 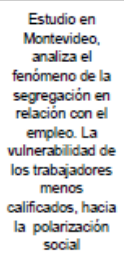 & $\begin{array}{l}\text { Analiza las } \\
\text { acciones } \\
\text { asumidas por el } \\
\text { Gobiemo para } \\
\text { disminuir la } \\
\text { Segregación } \\
\text { educativa. Estudio } \\
\text { realizado en la } \\
\text { cuidad de } \\
\text { Montevide. } \\
\text { durante } 1996- \\
2004\end{array}$ & 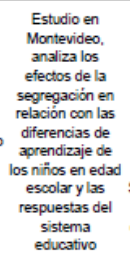 &  & 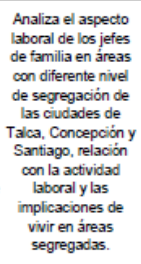 & 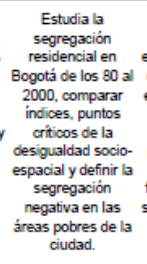 & 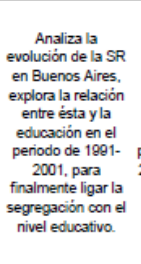 & $\begin{array}{l}\text { Estudio que } \\
\text { cuantifica la } \\
\text { segregación } \\
\text { existente en } \\
\text { Argentina del } \\
\text { periodo de 1981- } \\
\text { 2001, en base al } \\
\text { uso de zonas } \\
\text { censales }\end{array}$ & 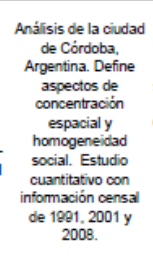 & 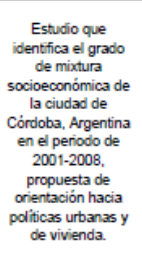 & & 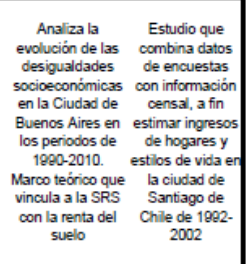 \\
\hline & Rodriguez Vignolit & & Duhau & Marengo & & $\begin{array}{l}\text { Groisman y } \\
\text { Suárez }\end{array}$ & Paul Peters & $\begin{array}{c}\text { Rodriguez } \\
\text { Merkel }\end{array}$ & $\begin{array}{c}\text { Garin, Salvo y } \\
\text { Bravo }\end{array}$ & $\begin{array}{c}\text { Groisman y } \\
\text { Suárez }\end{array}$ & Pérren & & Molinatti & $\begin{array}{c}\text { Orellanay } \\
\text { Osorio }\end{array}$ & & Molinatti \\
\hline & 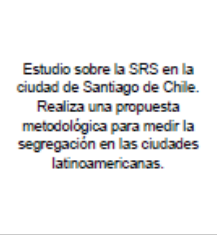 & 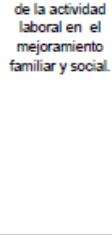 & 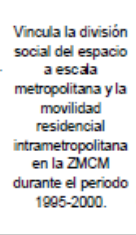 & 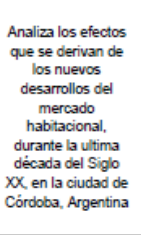 & &  & 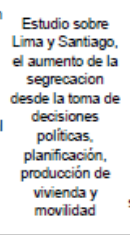 & $\begin{array}{c}\text { Mide la SRS } \\
\text { (desigualdad, } \\
\text { exposicion, } \\
\text { concentración y } \\
\text { dustering) } \\
\text { prionizando la } \\
\text { distrucuón } \\
\text { espacial de los } \\
\text { grupos de menor } \\
\text { nivel } \\
\text { socioeconómico de } \\
1991-2001\end{array}$ & 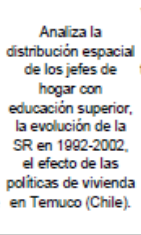 & 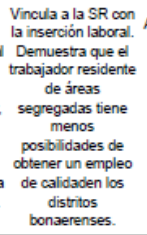 & 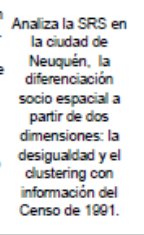 & &  & 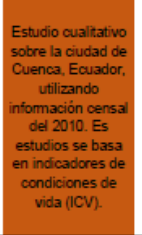 & & 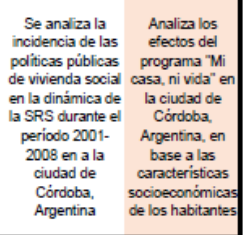 \\
\hline & Swampa & & & & & & & & & & & & $\begin{array}{l}\text { Sabatini y } \\
\text { Wormald }\end{array}$ & Gasparini & & \\
\hline & 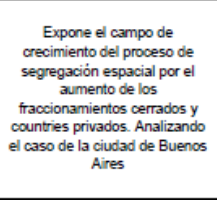 & & & & & & $\begin{array}{l}\text { Articulo que } \\
\text { presentan un } \\
\text { análisis } \\
\text { cualitatitivo }\end{array}$ & & $\begin{array}{l}\text { Articulo que } \\
\text { presentan un } \\
\text { análisis mixto }\end{array}$ & & 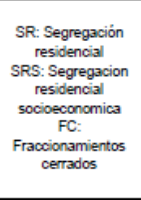 & & 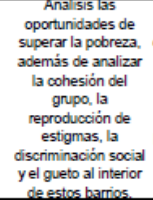 &  & & \\
\hline
\end{tabular}

Fuente: Elaboración propia, con base en la revisión bibliográfica 
Marco A. M. Ortega

Laura B. Rodríguez
Cadernos Prolam/USP, v.16, n.31, p.160-188, jul./dez.2017

DOI: 10.11606/issn.1676-6288.prolam.2017.140636

Esquema 3. Línea de tiempo que aborda algunos de los estudios realizados sobre la SRS en México desde principios del siglo XXI

\begin{tabular}{|c|c|c|c|c|c|c|c|c|c|c|c|c|}
\hline & & & & \multicolumn{2}{|l|}{ Caprón y González } & \multicolumn{3}{|c|}{ Sandoval Hemández $\quad$ Saravi } & Castillo y Villar & \multicolumn{3}{|l|}{ Rubalcava y Schteingart } \\
\hline & & & & 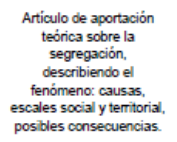 & & $\begin{array}{l}\text { Revisión critica de los } \\
\text { diferentes estudios que } \\
\text { se han desarrollado en el } \\
\text { AMM sobre pobreza. } \\
\text { desigualdady y. } \\
\text { marginación }\end{array}$ & 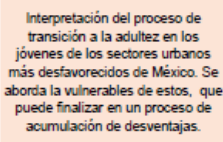 & & 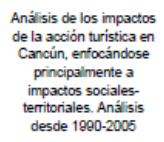 & \multicolumn{3}{|l|}{  } \\
\hline & Cabrales, Canosa & Cabrales & & Cabrales & Nuñéz Miranda & Salinas Arreortua & González Arellano & & Perez Campuzano & Monkkonen & Duhau & \\
\hline &  & 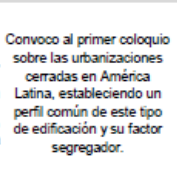 & & 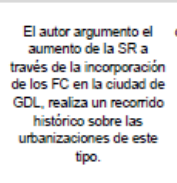 & 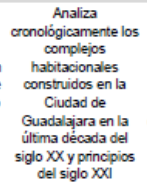 & $\begin{array}{l}\text { Análisis técicoo desde la } \\
\text { perspectiva de la } \\
\text { acummulacion del capital } \\
\text { para profindizar los } \\
\text { efectos de la segregación } \\
\text { presente en la ZMCM }\end{array}$ &  & & 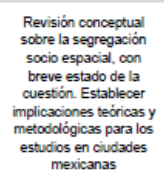 & 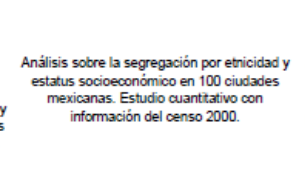 & 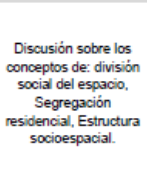 & \\
\hline 2000 & 2001 & 2004 & 2005 & 2006 & 2007 & 2008 & 2009 & 2010 & 2011 & \multirow[t]{2}{*}{2012} & 2013 & 2017 \\
\hline \multirow{2}{*}{\multicolumn{13}{|c|}{$\begin{array}{l}\text { Aportaciones conceptuales y teoricas } \\
\text { LINEA DEL TIEMPO SOBRE ESTUDIOS DE SEGREGACIÓN RESIDENCIAL SOCIECONOMICA EN MÉXICO }\end{array}$}} \\
\hline & & & & & & & & & & & & \\
\hline \multicolumn{13}{|c|}{ Aportaciones metodologicas o aplicación de metodología } \\
\hline $\begin{array}{l}\text { Ruvaleabay } \\
\text { Schteingart }\end{array}$ & Schteingart & $\begin{array}{l}\text { Aceves, De la Torre, } \\
\text { Safa }\end{array}$ & $\begin{array}{l}\text { Carmen } \\
\text { venegas }\end{array}$ & Alegria & $\begin{array}{l}\text { González } \\
\text { Arellano }\end{array}$ & Saravi & Baños & Schteingart & Gonzalez Arrellano & Sánchez Peña & Fuentes y Flores & $\begin{array}{c}\text { Dominguez } \\
\text { Aguilar }\end{array}$ \\
\hline \multirow[t]{5}{*}{ 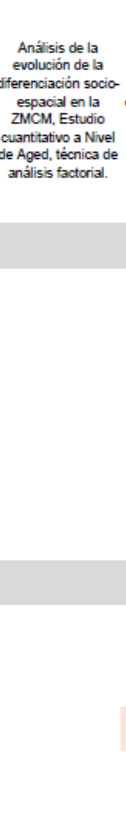 } & 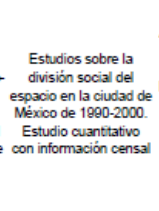 & 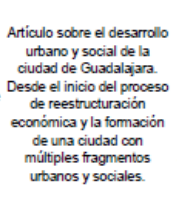 & $\begin{array}{l}\text { Estudios sobre los } \\
\text { niveles de } \\
\text { población mas } \\
\text { segregados de la } \\
\text { ciudad de } \\
\text { Guadalajara en los } \\
\text { anos de } 1900-2005\end{array}$ & 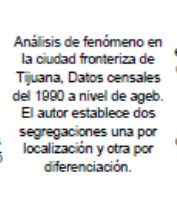 & 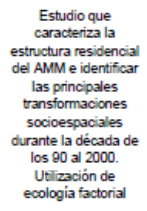 & $\begin{array}{l}\text { El autor habla de la } \\
\text { necesidad abrupta de las } \\
\text { cimmensiones objetivas y } \\
\text { simbólica en los estudios } \\
\text { sobre segregación } \\
\text { urtana. Estugio para la } \\
\text { ciudad de México sobre } \\
\text { estigmas Territoriales. }\end{array}$ & 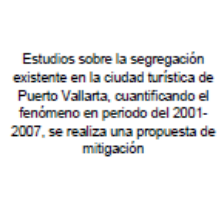 & 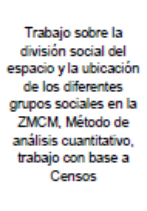 & 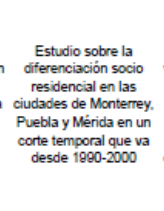 &  & 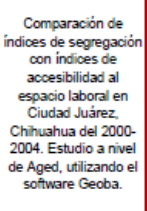 & 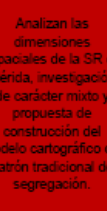 \\
\hline & & & $\begin{array}{l}\text { González } \\
\text { Hemandez }\end{array}$ & Fuentes y Cervera & & Vilatta & Ariza y Solis & $\begin{array}{l}\text { Pérez } \\
\text { Campuzano }\end{array}$ & Aguilar $y$ Mateos & Sánchez Peña & Alvizo Carranza & \\
\hline & \multirow[t]{3}{*}{  } & &  & 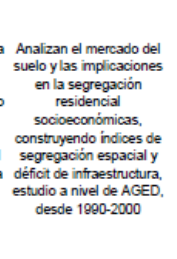 & & 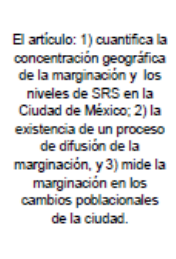 & 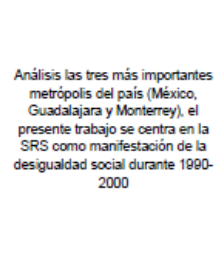 & 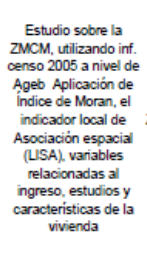 & 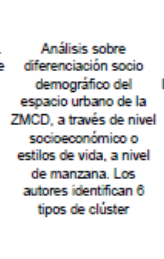 & 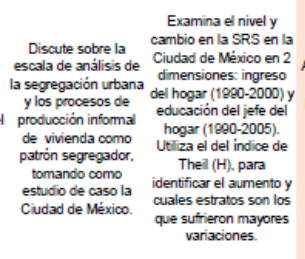 & 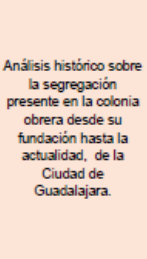 & \\
\hline & & & & & & & & $\begin{array}{c}\text { Pérez } \\
\text { Campuzano }\end{array}$ & Aparicio & \multicolumn{3}{|l|}{ Gónzalez Gómez } \\
\hline & & $\begin{array}{l}\text { Articaulo que presentan un } \\
\text { analisis cualititivo }\end{array}$ & & $\begin{array}{l}\text { Articulo que presentan un } \\
\text { analisis mixto }\end{array}$ & & & &  &  & \multicolumn{3}{|l|}{ 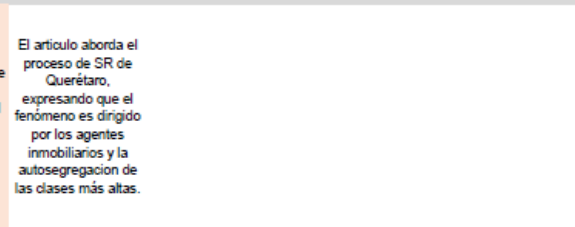 } \\
\hline
\end{tabular}

Fuente: Elaboración propia, con base en la revisión bibliográfica 


\section{LA SEGREGACIÓN RESIDENCIAL SOCIOECONÓMICA EN AMÉRICA}

\section{LATINA}

Si bien, la segregación étnica y racial ha sido la forma más reconocida y estudiada del fenómeno a nivel mundial, la segregación por cuestiones socioeconómica es la forma más extendida en América Latina (SABATINI, 2006). Donde el motivo principal de segregación es el factor económico y se denomina Segregación Residencial Socioeconómica (SRS), en este enfoque los aspectos étnicos, religiosos, culturales, entre otros, toman un papel secundario para dar prioridad al factor económico en lo que respecta al poder adquisitivo de las personas o familias.

Este factor es vital para el análisis y la comprensión de los actuales procesos de discriminación, desigualdad, segregación y distribución residencial de la población en las ciudades de América Latina, en ese sentido Rodríguez Merkel conceptualiza la SRS, como:

el proceso mediante el cual los grupos sociales de mayor poder restringen, condicionan o limitan -a través de distintos mecanismos, y de manera no siempre consciente e intencional- las oportunidades de acceso al suelo urbano a los grupos de menor poder, resultando en su distribución desigual u otras formas de separación en el espacio físico de la ciudad (2014 pág. 11).

De manera que la SRS la podemos entender, ante todo, como una cuestión de poder económico, destacando el acceso que esta condición brinda a las distintas esferas de la vida social, política, cultural y económica en una ciudad. En términos espaciales lo anterior se traduce en la organización social de acuerdo con el poder y las capacidades económicas. Así, entre mayor sea el poder económico con que se cuente, mayor capacidad de "organizar" el espacio se tendrá.

\section{Características del fenómeno}

Diversos investigadores del fenómeno en América Latina (SABATINI, 2006; ARRIAGADA, RODRÍGUEZ VIGNOLI, 2004) evidencian tres dimensiones de la segregación:

- El grado de concentración espacial de los grupos sociales en zonas específicas de la ciudad. 
Marco A. M. Ortega

Laura B. Rodríguez
Cadernos Prolam/USP, v.16, n.31, p.160-188, jul./dez.2017

DOI: 10.11606/issn.1676-6288.prolam.2017.140636

- La homogeneidad social de las distintas áreas de las ciudades, o dicho de otra manera la proximidad física entre los espacios residenciales de los diferentes grupos sociales.

○ El prestigio o desprestigio social, o estigma, de las distintas áreas o barrios de la ciudad.

La primera es una dimensión objetiva y voluntaria, potencialmente positiva para la construcción y preservación de identidades, capital social y externalidades de vecindad (SABATINI, 2006). Por su parte la segunda dimensión tiene una connotación de carácter negativo, además de ser involuntaria y excluyente, ocasionando procesos de descomposición y exclusión social en los barrios pobres (KAZTMAN, 2001). Estas dos, a decir de Rodríguez Vignoli, son dimensiones objetivas y cuantificables, que nos permiten construir indicadores de segregación residencial (2001).

Mientras que la tercera dimensión aborda aspectos de carácter subjetivos, intenta determinar el grado de "prestigio" de los barrios que componen la ciudad y la formación de estigmas territoriales asignados por la población a algunos de los vecindarios, esta dimensión llega a tornarse negativa en el caso de estigmatización de los barrios pobres (SARAVÍ, 2008).

Por consiguiente, se tiene que la segregación:

○ Es un fenómeno, no un problema, por lo tanto, es un proceso, no una situación.

○ Forma parte de la realidad social y por ello el espacio adquiere significado y juega distintos roles en los procesos sociales.

- Contribuye a formar identidades sociales, determinando el acceso diferenciado de la población y constituye o da lugar a "estilos de vida".

Bajo este escenario la segregación es un fenómeno de múltiples facetas, primeramente, actúa en el lugar de residencia -se busca compartir vecindario solo con grupos socioeconómicos similares al nuestro-, posteriormente se extiende en el ámbito territorial donde la sociedad realiza sus actividades cotidianas - como trabajo, estudio, recreación, entre muchas otras, se busca interactuar con personas semejantes en cuanto al nivel socio económico (educación, profesión, capacidad adquisitiva) y finalmente en el espacio interactivo -relacionándonos solo con aquellos que consideramos iguales a nosotros en estatus social y económico-, siendo las relaciones que establecen las redes sociales en la ciudad. Por lo tanto, es importante esclarecer las repercusiones 
Marco A. M. Ortega

Laura B. Rodríguez
Cadernos Prolam/USP, v.16, n.31, p.160-188, jul./dez.2017

DOI: 10.11606/issn.1676-6288.prolam.2017.140636

tanto positivas como negativas del fenómeno, para llegar a un conocimiento pleno de la segregación.

\section{$>$ Causas}

El estudio de la segregación con base en aspectos socioeconómicos ha tenido un gran auge en las últimas décadas en los países de América Latina. El fenómeno de la segregación no es nuevo para estas latitudes, sin embargo, los procesos de reestructuración económica y laboral dieron lugar a una nueva dimensión del fenómeno que conlleva a establecer una clara segmentación del espacio urbano a partir de las capacidades económicas de los habitantes. De Mattos (2006, pág. 2) considera que actualmente estamos viviendo una "nueva etapa de modernización capitalista; (que ha traído) una verdadera metamorfosis que comenzó a afectar (a la ciudad) tanto a su organización y funcionamiento, como a su morfología” (2006 pág. 2).

El resultado son ciudades divididas, duales, fragmentadas, polarizadas o que asemejan archipiélagos de islas (CASTELLS, 1999; BORSDORF, 2003; JANOSHCKA, 2002). A continuación, con base en las aportaciones de diversos investigadores, se abordan en síntesis algunos de los aspectos más sobresalientes del fenómeno:

A principios de los años ochenta, los países latinoamericanos sufrieron una transformación en el modelo económico impulsado por la aplicación de una estrategia macroeconómica de liberalización de los mercados. "El cambio a un nuevo paradigma económico, basado en el neoliberalismo (...) La retirada del Estado, la privatización y la desregulación permitieron a los inversores, planificadores y ciudadanos, mayores libertades” (BORSDORF, 2003 pág. 1). Este nuevo esquema económico y político, acelera los procesos de producción y consecuentemente los fenómenos urbanos y sociales que ocurren en las ciudades.

Por otro lado, las transformaciones del mercado laboral, unidas a los procesos de globalización y el crecimiento de las desigualdades sociales fundamentaron el desarrollo de la teoría de la ciudad dual, que propone la formación de sociedades y ciudades duales durante la última década del siglo XX y principios del XXI (CASTELLS, 1999). Al respecto, De Mattos (2002) debate el concepto de Ciudad Dual, como un modelo de diferenciación socioespacial de núcleos urbanos sujetos a la polarización creciente entre los integrados y los excluidos; poniendo en crisis la tradicional 
Marco A. M. Ortega

Laura B. Rodríguez
Cadernos Prolam/USP, v.16, n.31, p.160-188, jul./dez.2017

DOI: 10.11606/issn.1676-6288.prolam.2017.140636

división social heredada de la etapa del estado de bienestar y caracterizada por el imperio de la clase media con leves variaciones hacia arriba y hacia abajo.

En ese sentido, se establece que la evolución del mercado laboral reduce la proporción de ocupaciones protegidas y estables, aumentando las disparidades de ingreso entre trabajadores de alta y de baja calificación, y se intensifican los problemas de desempleo y subempleo, que afectan en particular a estos últimos. Al respecto Saskia Sassen (2000) señala que este cambio es necesario para el nuevo orden tardío capitalista, donde los trabajos de bajo nivel salarial son claves para el crecimiento económico, ello convierte al declive social en algo complementario al desarrollo, y no como un indicativo de decadencia.

Diversos investigadores del tema en América Latina concuerdan en la que SRS es un fenómeno social en aumento, a causa de la combinación de:

○ Los cambios estructurales operados a escala mundial desde los años ochenta (globalización, desregulación, libre comercio de mercados), que han tendido a beneficiar a algunos segmentos de la población y a perjudicar a otros, con el consiguiente aumento en las disparidades socioeconómicas (DE MATTOS, 2002)

- La liberalización de los mercados de tierras, que encarecieron el acceso al suelo y que permitieron una correspondencia más estrecha entre el valor del suelo y el nivel socioeconómico de la población que lo ocupa (JARAMILLO, 2009).

- Las crecientes condiciones de inseguridad en las ciudades y por consiguiente la búsqueda de lugares protegidos por parte de los grupos con mayores recursos (CABRALES BARAJAS; CANOSA ZAMORA, 2001).

- El común denominador social que considera a las áreas habitacionales privadas y exclusivas como los mejores espacios para vivir y por consiguiente el lugar de los grupos socialmente privilegiados (JANOSHCKA, 2002).

\section{Consecuencias}

Se puede establecer que las relaciones entre sociedad, espacio y poder adquisitivo han dado lugar a altos niveles de segregación y desigualdad en las ciudades de América Latina. Esto implica que los distintos estratos socioeconómicos tienden a compartir el vecindario sólo con personas del mismo estatus o nivel, lo cual, a su vez, genera repercusiones en varios sentidos, a continuación, se señalan algunos de los efectos resultantes: 
Marco A. M. Ortega

Laura B. Rodríguez
Cadernos Prolam/USP, v.16, n.31, p.160-188, jul./dez.2017

DOI: 10.11606/issn.1676-6288.prolam.2017.140636

- La segregación, aislamiento y casi confinación de los estratos socioeconómicos bajos. Limitando las oportunidades de mejorar su calidad de vida al estrechan sus horizontes de posibilidades. Destacan los problemas de accesibilidad y la carencia de servicios y equipamientos urbanos de calidad en sus lugares de residencia (KATZMAN Y RETAMOSO 2005).

- Se refuerza el pensamiento de vivir entre iguales, incentivando la estigmatización social. Los segmentos de mayores ingresos se aíslan y establecen procesos de socialización entre ellos de acuerdo con su estatus o nivel socioeconómico (RODRÍGUEZ MERKEL, 2014).

- Se revitaliza la utilización de mecanismos territoriales (muros, rejas, casetas de vigilancia) que refuerzan el aspecto segregador (CABRALES BARAJAS; CANOSA ZAMORA, 2001).

- Se incrementa el deterioro de la vida comunitaria y la capacidad de acción colectiva, asociándose con el aumento de la malignidad de la segregación, violencia y desconfianza (SABATINI, 2006).

- Se refuerzan procesos de gentrificación que conllevan al desplazamiento de población marginal de las áreas degradadas, que son sustituidas por personas de mayor nivel socioeconómico revalorizando los espacios (SALINA ARREORTUA, 2013).

- Se dinamiza la estratificación del espacio público, que generan nuevos esquemas de interacción urbana a través del montaje de espacios fragmentados (MUXI, 2006).

\section{LA SRS Y SU RELACIÓN CON LA DESIGUALDAD ECONÓMICA EN MÉXICO}

El conjunto de argumentos hasta ahora presentados sobre la SRS, nos llevan a formular las siguientes interrogantes: ¿Cuál es la percepción de la población mexicana con respecto al fenómeno de la segregación? y, ¿cómo convivimos con ella socialmente? A lo largo del documento se muestra a la segregación, como un proceso complejo de múltiples dimensiones, conexiones, consecuencias e impactos, que involucra no solo a los estratos inferiores o superiores de la escala socioeconómica, sino que involucra a toda la sociedad, donde la segregación se inserta, de distintas formas, en procesos de diferenciación, desigualdad y/o exclusión. 
Marco A. M. Ortega

Laura B. Rodríguez
Cadernos Prolam/USP, v.16, n.31, p.160-188, jul./dez.2017

DOI: 10.11606/issn.1676-6288.prolam.2017.140636

Con el fin de ejemplificar las conexiones entre los conceptos mencionados con la SRS se retoma la Encuesta Nacional sobre Discriminación; a continuación, se muestran algunos de los resultados obtenidos de las dos versiones realizadas hasta ahora: 2005 y 2010 por la CONAPRED ${ }^{3}$. Los aspectos por considerar son: i) el sentir de los mexicanos sobre la segregación, ii) la desigual distribución de la riqueza y iii) la exclusión de algunos grupos socioeconómicos. Según los datos arrojados, la población mexicana percibe que sus derechos han sido limitados o no respetados en su mayoría por carecer de dinero, con ello se profundizar el sentimiento de ser diferentes y de pertenecer a un grupo social excluido (ver gráfico 1).

Grafico 1. Apreciación de la población mexicana sobre las causas por las cuales sus derechos se han visto limitados o no respetados

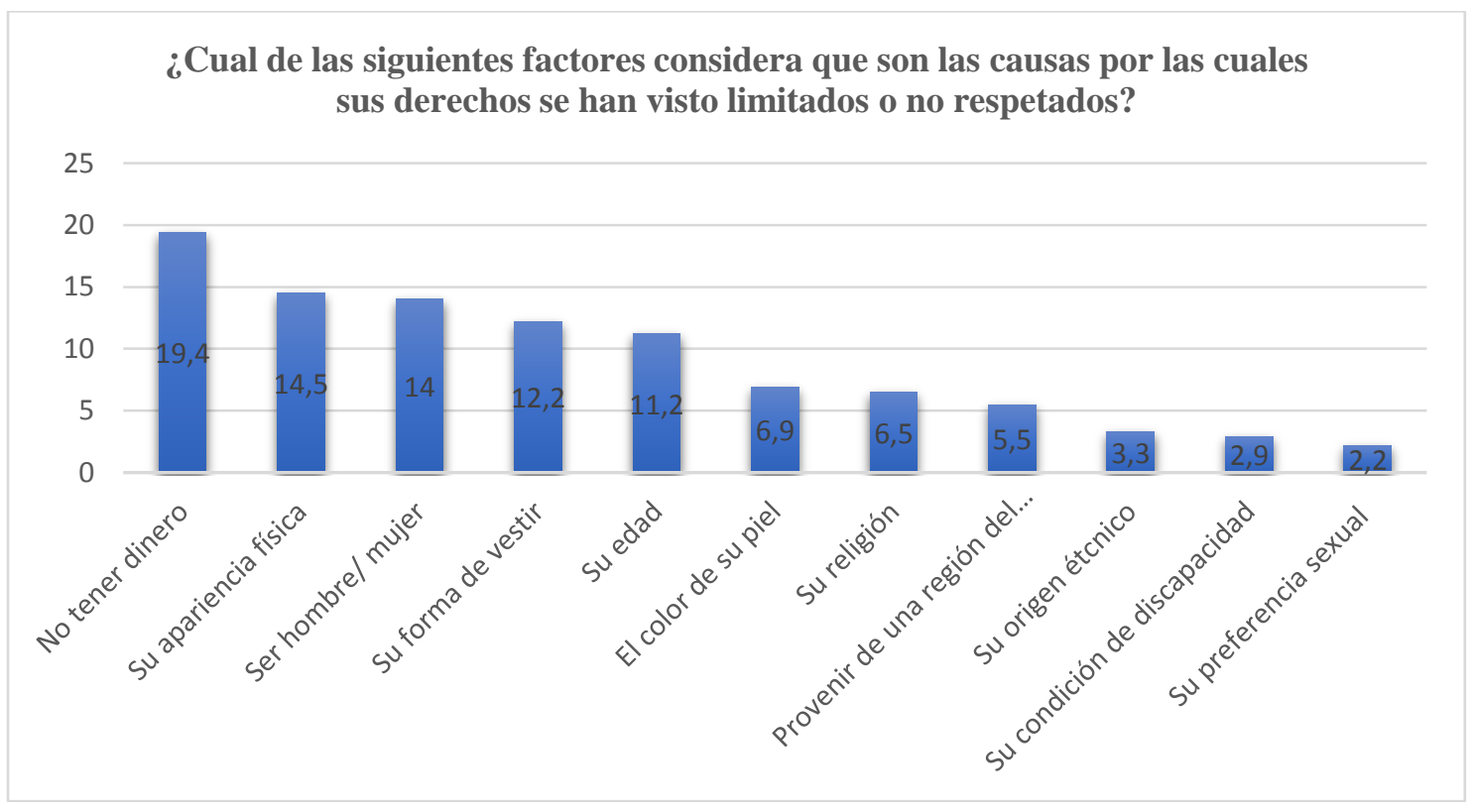

Fuente: Información obtenida de la Encuesta Nacional sobre Discriminación (CONAPRED, 2005)

Para el año 2010 los datos proporcionados por la misma encuesta muestran que la percepción sobre las disparidades socioeconómicas lejos de disminuir se incrementa (ver gráfica 2). Duhau señala que "la división social del espacio tiene como componente fundamental la característica de ser la expresión espacial de la estructura de clases o de la estratificación social” (2003 pág. 179). Esa relación jerárquica es intuida por la sociedad mexicana, siendo consciente de las divisiones que crea la riqueza.

\footnotetext{
${ }^{3}$ Órgano de Estado Mexicano, creado por la Ley Federal para Prevenir y Eliminar la Discriminación, aprobada el 29 de abril de 2003. El Consejo es la institución rectora para promover políticas y medidas tendientes a contribuir al desarrollo cultural y social y avanzar en la inclusión social y garantizar el derecho a la igualdad.
} 
Marco A. M. Ortega

Laura B. Rodríguez
Cadernos Prolam/USP, v.16, n.31, p.160-188, jul./dez.2017

DOI: 10.11606/issn.1676-6288.prolam.2017.140636

De acuerdo con información obtenida por CONAPRED (2010) seis de cada diez personas en nuestro país consideran que la riqueza es el factor que más divide a la sociedad; este pensamiento queda aún más evidente para los estratos socioeconómicos Medio alto/Alto, al igual que para el estrato Muy bajo, con los porcentajes del 63.9\% y $60.5 \%$ respectivamente (ver gráfico 3). De manera que el factor económico juega un papel sustancial en la segregación y a su vez la segregación juega un papel decisivo en la formación de una estructura espacial y social desigual y fragmentada en las ciudades de México. Las clases dominantes condicionan a las clases sociales menos favorecidas el acceso a mejores áreas de residencia (BORSDORF, 2003), por consiguiente los grupos sociales de menor poder adquisitivo tienen limitaciones para acceder al suelo urbano, así como disminuye las oportunidades de acceder a vivienda, educación, salud, servicios e infraestructura básica de calidad.

Grafico 2. Percepción sobre los factores que dividen a las personas que viven en un mismo lugar, según la



población mexicana

Fuente: Información obtenida de la Encuesta Nacional sobre Discriminación en México (CONAPRED, 2010)

La sociedad mexicana se caracteriza por una profunda desigualdad en las condiciones de vida de la población, la cual se expresa en múltiples y diversos indicadores: ingreso económico, nivel de educación, tipo de actividad económica, acceso a servicios de salud, seguridad social, entre 
Marco A. M. Ortega

Laura B. Rodríguez
Cadernos Prolam/USP, v.16, n.31, p.160-188, jul./dez.2017

DOI: 10.11606/issn.1676-6288.prolam.2017.140636

otros (RUVALCABA; SCHTEINGART, 2012). México presenta la irritante paradoja de contar con personas que se ubican entre las más ricas del mundo, al mismo tiempo que cerca de la mitad de su población vive en condiciones de pobreza, esto ha llevado a hablar de una clara polarización de la estructura social entre una ciudadanía de primera y de tercera clase (SARAVÍ, 2008).

Finalmente, en la gráfica 4 se muestran si los mexicanos consideran los ingresos percibidos como suficientes o no para cubrir las necesidades básicas; donde el 56.8\% de los encuestados considera que no, $20 \%$ considera que más o menos son suficientes, $3.7 \%$ manifiesta no tener ingresos y solo el 19.3\% sostiene que son suficientes sus ingresos (ver gráfica 4).

\section{Grafico 3. Percepción sobre si la riqueza es la que provoca más divisiones entre población por nivel socioeconómico}

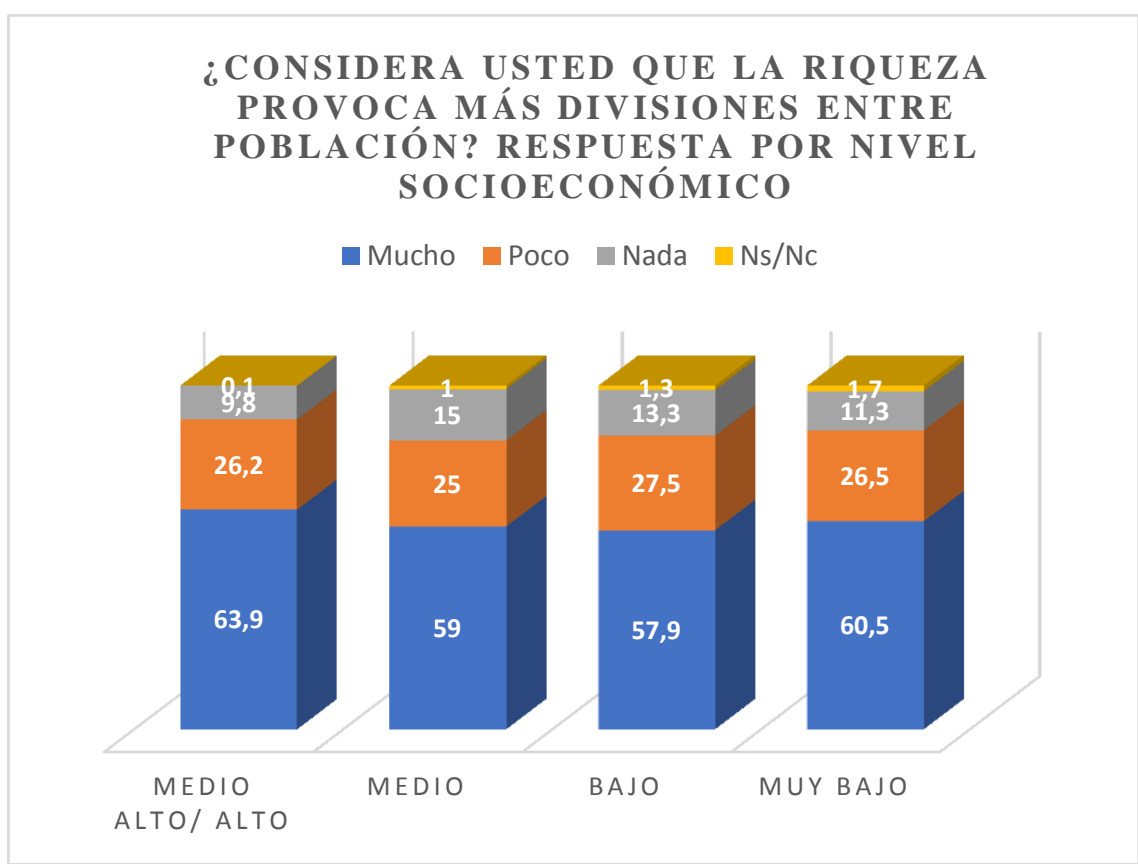

Fuente: Información obtenida de la Encuesta Nacional sobre Discriminación en México (CONAPRED, 2010)

Los resultados indican que la mayoría de la población en México determina que sus ingresos no son suficientes para satisfacer sus necesidades, por lo tanto su situación economica y social se ve reforzada y agudizada con el paso del tiempo. Dando como resultado el empobrecimiento del capital humano en el aspecto educativo, económico y social; lo anterior conlleva a que en los hogares en esta situación se mantenga o aumente esa condición de marginalidad, estableciendo un círculo vicioso de pobreza y marginación (SARAVÍ, 2008), por lo tanto se tiene que la dimensión de pobreza potencia la dimensión funcional de dicha condición social. 
Marco A. M. Ortega

Laura B. Rodríguez
Cadernos Prolam/USP, v.16, n.31, p.160-188, jul./dez.2017

DOI: 10.11606/issn.1676-6288.prolam.2017.140636

Grafico 4. Percepción de la población en general sobre si sus ingresos son suficientes

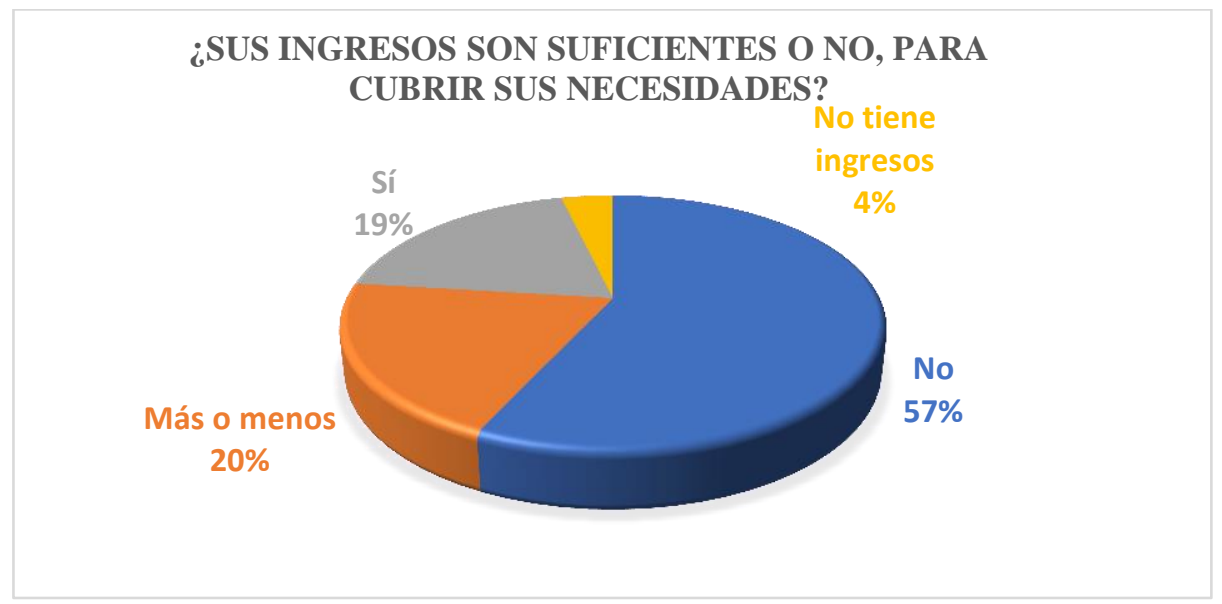

Fuente: Información obtenida de la Encuesta Nacional sobre Discriminación en México (CONAPRED, 2010)

\section{REFLEXIONES FINALES}

La división del espacio por nivel socioeconómico es decisiva en la formación de comunidades segregadas en México. Por ello es importante señalar el avance obtenido en la investigación de este tema; en la actualidad son numerosos los estudios que tratan de profundizar en el conocimiento del fenómeno de la SRS y sus implicaciones. Siendo fundamental seguir realizando este tipo de estudios para obtener una lectura clara y precisa del fenómeno, así como de las implicaciones específicas, los factores espaciales y sociales que potencializan la segregación y de esta manera conocer la realidad urbana.

El artículo presenta una síntesis sobre la evolución de los estudios sobre la SRS en América Latina a través de esquemas en forma de línea del tiempo, de la cual podemos sustraer los siguientes apuntes; i) a partir de los primeros años del siglo XXI los estudios sobre la segregación son una importante línea de investigación, profundizando en la conceptualización del fenómeno en la realidad latinoamericana, ii) se explican las características, causas y repercusiones del fenómeno, iii) se proponen metodologías de corte cuantitativo y escalas de valoración de la segregación y finalmente, iv) los estudios más actuales tratan de abordar el aspecto subjetivo de la segregación realizando investigaciones de enfoque cualitativo.

Para finalizar, podemos concluir que la segregación es el resultado de la interacción entre las distancias espaciales que unen a iguales y separan a diferentes, y la construcción mental del "otro" y su hábitat; contribuyendo a la des-socialización de la ciudad. Una de las interrogaciones que se 
Marco A. M. Ortega

Laura B. Rodríguez
Cadernos Prolam/USP, v.16, n.31, p.160-188, jul./dez.2017

DOI: 10.11606/issn.1676-6288.prolam.2017.140636

deriva del panorama descrito hasta ahora, es entonces, cómo es posible esta coexistencia en un mismo espacio urbano, la coexistencia no sólo de sectores de población con tantas diferencias, sino también profundamente desiguales. Para David Harvey, la solución es clara, es esencial trabajar hacia la democratización del derecho a la ciudad y a la formación de un gran movimiento social que haga que los desposeídos puedan tomar el control de la ciudad de la que han sido excluidos desde hace tanto tiempo (HARVEY, 2011).

Esta iniciativa, ha tenido un eco importante, en diferentes partes de la esfera mundial. Actualmente, la mayoría de los países, enfrentan un crecimiento constante de la población urbana en situación de crisis; por lo tanto, los debates se multiplican y llaman la atención sobre las consecuencias negativas del proceso social de segregación. Por iniciativa de la ONU algunos países industrializados se reúnen, para discutir al respecto, ejemplo de ello, fue el Foro Social Mundial de Porto Alegre en 2001 que intentó reunir reivindicaciones sobre vivienda y medio ambiente válidas para todo el planeta y redactar la "Carta Mundial por el Derecho a la Ciudad", basada en los preceptos de solidaridad, libertad, igualdad, dignidad y justicia social. Al igual que Habitat International Coalition (HIC) publicó en 2010 "Ciudades para todos, por el derecho a la ciudad, propuestas y experiencias", asentado en un enfoque de la vida urbana con raíces en el tejido latinoamericano en particular.

Sin embargo, en el actual contex to de urbanización acelerada y modelo capitalista este derecho permanece por tanto como un elemento idealizado, que forma parte de un mundo 'digno de los seres humanos', pero solo reservado para algunos, como subraya David Harvey "es notorio que el derecho a la ciudad está cayendo cada vez más en manos privadas o semiprivadas” (2011 pág. 179). Por lo tanto, el arduo compromiso de formar una sociedad en conjunto donde el derecho a la ciudad prevalezca para todos, sin importar condiciones raciales, étnicas, socioeconómicas, religiosas, de género, entre muchos otros, es incompleto y fragmentado. Por lo tanto, se concluye con las palabras de Duhau que nos invita a fomentar la "sociabilidad urbana" (2003 pág. 179), que remite a "la posibilidad de interacción entre grupos sociales diferentes, hacia la construcción de una ciudad completa de la cual todos formemos parte”.

\section{REFERÊNCIAS}

ABRAMO, Pedro. La teoría económica de la favela: cuatro notas sobre la localización residencial de los pobres y el mercado inmobiliario informal. Ciudad y Territorios: Estudios territoriales, Vol. XXXV, No. 136-137, España, Verano-otoño. Ministro de Fomento. 2003. 
Marco A. M. Ortega

Laura B. Rodríguez
Cadernos Prolam/USP, v.16, n.31, p.160-188, jul./dez.2017

DOI: 10.11606/issn.1676-6288.prolam.2017.140636

AMATO, Peter. El papel de la elite y patrones de asentamiento en la ciudad latinoamericana [Publicación periódica]. - [s.1.] : Revista Interamericana de Planificación, núm. 13 y 14. Vol. IV.1970

ARRIAGADA C.; VIGNOLI, Rodríguez. Segregación residencial en áreas metropolitanas de América Latina: magnitud, características, evolución e implicaciones de política. Serie Población y Desarrollo, 47. Santiago, Chile, 2003.

BAÑOS FRANCIA, Alfonso. Segregación Residencial en el Espacio Turístico de Puerto Vallarta. Guadalajara. Universidad de 2009. Bell, Wendell. A probability model for the measurement of ecological segregation. Social Forces. p. 357-364, 1954. BORSDORF, Axel. Como modelar el desarrollo y la dinamica de la ciudad latinoamerica. Eure, vol. XXIX, No. 86. p 37-49, 2003.

CABRALES BARAJAS, Luis Felipe; CANOSA ZAMORA, Elia. Segregación residencial y fragmentacion urbana: los fraccionamientos cerrados en Guadalajara. Espiral, Estudios sobre estados y sociedad. Vol. VII, No. 20, p. 223-253, 2001.

CABRALES BARAJAS, Luis Felipe. Coloquio Latinoaméricano: Países abiertos, ciudades cerradas [Libro]. - Guadalajara : Universidad de Guadalajara - Unesco, 2002.

CABRALES BARAJAS, Luis Felipe. Segregacion social del Espacio: nuevos enfoques y patrones emergentes en México y Chile [Informe]. - México : UNAM, 2006.

CAlDEIRA PIRES DO RIO, Teresa. Ciudad de Muros, Sao Paulo: Universidad de San Paulo, 2000.

CASTELLS, Manuel. La cuestión urbana, Ciudad de México, Siglo XXI, 1999. 
Marco A. M. Ortega

Laura B. Rodríguez
Cadernos Prolam/USP, v.16, n.31, p.160-188, jul./dez.2017

DOI: 10.11606/issn.1676-6288.prolam.2017.140636

CONAPRED. Primera Encuesta Nacional para disminuir la discriminación, Ciudad de México, Consejo Nacional para prevenir la Discriminación en México, 2005.

Encuesta Nacional sobre Discriminación en México, Ciudad de México, Consejo Nacional para prevención la Discriminación en México, 2010.

DE MATTOS, C. Transformaciones de las ciudades latinoamericanas iImpactos de la globalización? Eure Vol. 28 No. 85. p.5-10, 2002.

.Modernización capitalista y transformación metropolitana en América Latina: 5 tendencias constitutivas, América Latina: ciudad, campo y turismo. Geraiges Amalia, Mónica Arroyo y Silveira. San Pablo, Brasil, CLACSO, 2006.

DUHAU, Emilio. División social del espacio metropolitano y movilidad residencial, Papeles de Población, vol. 9, núm. 36, p.161-210, abril-junio 2003.

DUNCAN O. D.; DUNCAN, B. A methodological analysis of segregation Indexes. American Socialogical Review, Number 20, p. 210-217, 1955.

GONZÁlEZ, Arellano Salomón. Ciudad Desigual: diferenciacion socioresidencial en las ciudades mexicanas, Ciudad de México, Cuajimapla, Plaza y Valdes Editores, 2011.

GROISMAN, Fernando. Segregación residencial socioeconómica en Argentina durante la recuperación Económica (2002-2007). Instituto de estudios Latinoamericanos. Madrid, España. DT. 03. 09. Universidad de Alcála, 2009.

HARVEY, David. “Le Droit a la ville”. Revue Internationale des livres et des idees. 2011.

JANOSHCKA, Michael. El nuevo modelo de la ciudad latinoamericana: fragmentacion y privatización. Revista latinoamericana de estudios Urbanos Regionales, EURE vol. 28 No. 85 Pontificia universidad Católica de Chile, 2002.

JARAMILLO, Samuel. Hacia una teoría de la renta del suelo urbano. CEDE, Bogotá. 2009. 
KAZTMAN, Ruben ; RETAMOSO, Alejandro. Segregación espacial, empleo y pobreza en Montevideo. Revista de la CEPAL, No. 85, Abril, p.131-148, 2005.

KAZTMAN, Rubén. Seducidos y abandonados: el aislamiento social de los pobres urbanos. Revista de la Cepal, No. 75, Diciembre, 2001.

MARCUSE, P. ; KEMPEN, R. Van. Globalizing Cities. A new Spatial order?. Oxford, Blackwell Publishers, 2000.

MARENGO, Cecilia; ELORZA, Ana. Tendencias de la segregación residencial socieconómica: El caso de Cordoba, Argentina, en el periodo de 2001-2008. Eure, vol. 140 No. 120 Mayo, p.111133,2014

MASSEY, D. S. ; DENTON, N. A. The dimensions of residential segragation. Social Forces, Number 67, p. 281-315, 1988

MOLINATTI, Florencia. Segregación residencial socioeconómica en la ciudad de Córdoba (Argentina): Tendencias y patrones. Revista INVI, vol. 28, núm. 79, septiembre-diciembre, p. 6194, 2013

MUXI, Zaida. La ciudad dual o el reto de la globalizacion sobre las ciudades. Ideas sostenibles, Espacio de reflexión y comunicación en desarrollo sostenible. Año 3, Vol. 14, 2006.

PARK, Robert E. The urban community as a Spatial Pattern and Moral Order. Chicago, University of Chicago, 1926.

PÉREZ, Campuzano Enrique. Segregación socioespacial en ciudades turísticas, el caso de Puerto Vallarta, México. Región y Sociedad. Vol. XXII. No. 49. El colegio de Sonora, p.143-176, 2010. 
Marco A. M. Ortega

Laura B. Rodríguez
Cadernos Prolam/USP, v.16, n.31, p.160-188, jul./dez.2017

DOI: 10.11606/issn.1676-6288.prolam.2017.140636

RODRIGUEZ MERKEL, Gonzalo Martín. Que es y que no es segregacion residencial, contribuciones para un debate pendiente [Publicación periódica] // Geo Crítica. Cuadernos críticos de geografía humana. Vol. XIX, No. 1079. - 2014. - págs. 5-29.

RODRIGUEZ, Vignoli Jorge. Segregacion residencial económica, ¿qué es?, ¿Comó se mide?, ¿que esta pasado?, ¿importa?. Santiago de Chile : Serie Población y territorio, No. 16 Proyecto Regional de Población CELADE-FNUAP, Centro Latinoamericano y Caribeño de Demografía, 2001.

RUVAlCABA, R. M ; SCHTEINGART, M. Ciudades dividias. Desigualdad y segregación social en México. Ciudad de México, El Colegio de México, 2012.

SABATINI, Francisco. La segregacion social del espacio en las ciudade de América Latina. Washington DC, Banco interamericano de Desarrollo, Division de programas sociales, 2006.

SABATINI, Francisco; CÁCERES, Gonzalo; CÉRDA, Jorge. Segregación residencial en las principales ciudades chilenas: tendencias de las tres últimas décadas y posibles cursos de acción. Eure,Vol. 27, No. 82, julio, 2001

SALINAS ARREORTUA, Luis Alberto. Gentrificación en la ciudad latinoamericana. El caso de Buenos Aires y Ciudad de México. GIECRYAL, Grupo interdisciplinario de estudios críticos y de América Latina, Vol. 4, num. 44, p. 283-307, 2013

SARAVÍ, Gonzalo A. Mundos aislados: segregación urbana y desigual en la ciudad de México. Eure, Vol. XXXIV, No. 103, p. 93-110, 2008.

SASSEN, Saskia. Cities in a word economy. Londres, Pine Forge Press, 2000.

SCHTEINGART, Martha. División social del espacio y segregación en la ciuda de México. Continuidad y cambios en las últimas décadas. Los grandes problemas de México, Desarrollo urbano y regional II. Garza Gustavo y Schteingart Martha. Ciudad de México, El colegio de 
Marco A. M. Ortega

Laura B. Rodríguez
Cadernos Prolam/USP, v.16, n.31, p.160-188, jul./dez.2017

DOI: 10.11606/issn.1676-6288.prolam.2017.140636

México, 2010.

SMOLKA MARTIM, Greenstein Rosalin ; SABATINI, Francisco. Seminario Internacional de Segregación en la ciudad [Informe]. - Cambridge, Massachusetts : Instituto Lincoln of Land Policy, 2001.

SVAMPA, Maristella. Los que ganaron. La vida en los contries y los barrios privados. Buenos Aires, Biblios, 2001.

VAN, Lindert Paul ; VERKOREN, Otto. Segregacion residecial y política en La Paz, Bolivia [Publicación periódica]. Vol.33, Boletín de estudios Latinoamericanos y del Caribe. 1982

WHITE, Michael J. Measurement of Spatial Segregation. The American Journal of Sociology, Vol. 88, No. 5, p.1008-1018, 1983.






\begin{tabular}{|c|c|c|c|}
\hline 2006 & $\begin{array}{l}\text { Tecco y } \\
\text { Váldez }\end{array}$ & \multicolumn{2}{|r|}{$\begin{array}{l}\text { Segregación residencial socioeconómica (SRS) e intervenciones para contrarrestar sus efectos } \\
\text { negativos: Reflexiones a partir de un estudio en la ciudad de Córdoba, Argentina. Cuadernos de } \\
\text { Geografía - Revista Colombiana de Geografía, núm. 15, pp. 53-66, } 2006\end{array}$} \\
\hline 2007 & $\begin{array}{l}\text { Sabatini y } \\
\text { Brain }\end{array}$ & \multicolumn{2}{|r|}{$\begin{array}{l}\text { Tres mitos y cinco claves de la segregación en las ciudades chilenas. Prourbana. No. 5, agosto, } \\
2007\end{array}$} \\
\hline 2008 & $\begin{array}{l}\text { Sabatini y } \\
\text { Brain }\end{array}$ & \multicolumn{2}{|r|}{$\begin{array}{l}\text { La segregación, los guetos y la integración social urbana: mitos y claves. 2008. Revista Eure, Vol. } \\
\text { XXXIV, N.․ 103, pp. 5-26, diciembre, } 2008\end{array}$} \\
\hline 2010 & Marcos & \multicolumn{2}{|r|}{$\begin{array}{l}\text { Distribución espacial de la población: conceptos y medidas. Serie Materiales didácticos, } \\
\text { Documentos No. } 20 \text {, agosto, } 2010\end{array}$} \\
\hline 2012 & $\begin{array}{l}\text { Ruíz Table y } \\
\text { López }\end{array}$ & \multicolumn{2}{|r|}{$\begin{array}{l}\text { El estudio de la segregación residencial en Santiago de Chile: revisión crítica de algunos problemas } \\
\text { metodológicos y conceptuales. Eure, Vol. 40, Núm. 119, pp. 25-48, enero,2012 }\end{array}$} \\
\hline \multirow[b]{2}{*}{2013} & Duhau & \multicolumn{2}{|r|}{$\begin{array}{l}\text { La división social del espacio metropolitano: una propuesta de análisis. Nueva Sociedad No 243, } \\
\text { enero-febrero, } 2013\end{array}$} \\
\hline & Linares & \multicolumn{2}{|r|}{$\begin{array}{l}\text { Las consecuencias de la segregación socio espacial: un análisis empírico sobre tres ciudades } \\
\text { medias bonaerenses (Ovalarrín, Pergamino y Tandil). Cuaderno Urbano. Espacio, Cultura, Sociedad } \\
\text { - Vol. } 14 \text { - N. } .914 \text {, Junio, } 2013\end{array}$} \\
\hline \multirow{2}{*}{2014} & Molinatti & \multicolumn{2}{|r|}{$\begin{array}{l}\text { Efectos de la segregación residencial socioeconómica sobre la reproducción adolescente. Ciudad de } \\
\text { Córdoba, } 2001 \text {. Población y Salud en Mesoamérica - Volumen 12, número 1, artículo 4, julio- } \\
\text { diciembre, } 2014\end{array}$} \\
\hline & $\begin{array}{l}\text { Rodríguez } \\
\text { Merkel }\end{array}$ & \multicolumn{2}{|r|}{$\begin{array}{l}\text { Que es y que no es segregación residencial. contribuciones para un debate pendiente. Revista } \\
\text { bibliográfica de Geografía y ciencias sociales. Vol. XIX, no 1079, junio, sin página, } 2014\end{array}$} \\
\hline \multirow[b]{2}{*}{2015} & López Morales & \multicolumn{2}{|r|}{$\begin{array}{l}\text { Suelo urbano y segregación residencial: Hacia una agenda de integración social para zonas } \\
\text { censales metropolitanas chilenas. Ciudades, No. 18, Vol. 1, pp. 197-213, } 2015\end{array}$} \\
\hline & Matossian & \multicolumn{2}{|r|}{$\begin{array}{l}\text { División social del espacio residencial y migraciones. El caso de San Carlos de Bariloche, Argentina. } \\
\text { EURE, vol. 41, No. 124, septiembre, pp. 163-184, } 2015\end{array}$} \\
\hline 2016 & $\begin{array}{l}\text { Marengo y } \\
\text { Elorza }\end{array}$ & \multicolumn{2}{|r|}{$\begin{array}{l}\text { Vivienda social en Córdoba: efectos de la segregación residencial y el crecimiento urbano (1991- } \\
\text { 2008). Revista INVI No. 86, mayo, Volumen 31, pp. 119-144, } 2016\end{array}$} \\
\hline \multicolumn{4}{|r|}{ Línea del tiempo América Latina / Aportaciones metodológicas } \\
\hline \multirow[t]{2}{*}{ AÑO } & \multicolumn{2}{|l|}{ AUTOR } & TITULO DE ARTÍCULO \\
\hline & \multicolumn{2}{|c|}{$\begin{array}{l}\text { Sabatini, Cáceres y } \\
\text { Cerdá }\end{array}$} & $\begin{array}{l}\text { "Segregación residencial en las principales ciudades chilenas: tendencias de las tres últimas } \\
\text { décadas y posibles cursos de acción", Eure, Santiago, v. 27. núm. 82, } 2001\end{array}$ \\
\hline \multirow[t]{2}{*}{2001} & \multicolumn{2}{|c|}{ Rodríguez Vignoli } & $\begin{array}{l}\text { Segregación residencial socioeconómica: ¿qué es? ¿cómo se mide? ¿qué está pasando? } \\
\text { ¿importa? CEPAL. Proyecto Regional de Población CELADE, Fondo de Población de las } \\
\text { Naciones Unidas (UNFPA). Santiago de Chile Serie Población y Desarrollo. } 2001\end{array}$ \\
\hline & \multicolumn{2}{|l|}{ Svampa, M. } & Los que ganaron. La vida en los countries y los barrios privados. Buenos Aires: Biblios. 2001 \\
\hline 2002 & \multicolumn{2}{|c|}{ Kaztman y Wormald } & $\begin{array}{l}\text { Los cambiantes rostros de la integración y exclusión social en cuatro áreas metropolitanas de } \\
\text { América Latina. Trabajo y ciudadanía. Cebra comunicación visual. } 2002\end{array}$ \\
\hline \multirow{2}{*}{2003} & \multicolumn{2}{|c|}{$\begin{array}{l}\text { Rodríguez Vignoli y } \\
\text { Arriagada }\end{array}$} & $\begin{array}{l}\text { Segregación residencial en áreas metropolitanas: magnitud, características, evolución e } \\
\text { implicaciones de política. CEPAL. Proyecto Regional de Población CELADE, Fondo de } \\
\text { Población de las Naciones Unidas (UNFPA). Santiago de Chile, } 2003\end{array}$ \\
\hline & \multicolumn{2}{|l|}{ Duhau } & $\begin{array}{l}\text { División social del espacio metropolitano y movilidad residencial. Papeles de Población, vol. 9, } \\
\text { núm. 36, abril-junio, pp. 161-210, } 2003\end{array}$ \\
\hline \multirow{2}{*}{2004} & \multicolumn{2}{|c|}{$\begin{array}{l}\text { Rodríguez Vignoli y } \\
\text { Arriagada }\end{array}$} & $\begin{array}{l}\text { Segregación residencial en la Ciudad latinoamericana. Revista EURE, Vol. XXIX, № 89, pp. 5- } \\
24,2004\end{array}$ \\
\hline & \multicolumn{2}{|l|}{ Marengo } & $\begin{array}{l}\text { Una aproximación a la segregación residencial, como punto de partida en la formulación de } \\
\text { política. Revista INVI No. 50, Volumen 19, pp. 167-183, } 2004\end{array}$ \\
\hline 2005 & \multicolumn{2}{|c|}{ Kaztman, Retamoso } & $\begin{array}{l}\text { Segregación espacial, empleo y pobreza en Montevideo. Revista de la CEPAL No. 85. Abril, } \\
2005\end{array}$ \\
\hline \multirow[b]{2}{*}{2006} & \multicolumn{2}{|c|}{ Kaztman, Retamoso } & $\begin{array}{l}\text { Segregación residencial en Montevideo: Desafíos para la equidad educativa. CEPAL. Reunión } \\
\text { de expertos sobre población y pobreza en América Latina y el Caribe, } 2006\end{array}$ \\
\hline & \multicolumn{2}{|c|}{ Groisman y Suárez } & $\begin{array}{l}\text { Segregación residencial en la Ciudad de Buenos Aires, Población de Buenos Aires, vol. 3, núm. } \\
\text { 4, octubre, pp. 27-37, } 2006\end{array}$ \\
\hline & \multicolumn{2}{|c|}{ Kaztman, Retamoso } & $\begin{array}{l}\text { Efectos de la segregación urbana sobre la educación en Montevideo. Revista de la CEPAL No. } \\
91, \text { abril, } 2007\end{array}$ \\
\hline 2001 & Paul Peters & & $\begin{array}{l}\text { Self-help housing and Informal Homesteading in Peri-Urban America: settlement identification } \\
\text { using digital imagery and GIS, Habitat International, pp. } 141-164,2007\end{array}$ \\
\hline
\end{tabular}


Marco A. M. Ortega

Laura B. Rodríguez

\begin{tabular}{|c|c|c|}
\hline \multirow{2}{*}{2008} & Rodríguez Merkel & $\begin{array}{l}\text { Segregación residencial socioeconómica en la Ciudad de Buenos Aires. Dimensiones y } \\
\text { cambios entre } 1991-2001 \text {. Población de Buenos Aires, vol. 5, n8, p. 7-30, } 2008\end{array}$ \\
\hline & Rodríguez Vignoli & $\begin{array}{l}\text { Movilidad cotidiana, desigualdad social y segregación residencial en cuatro metrópolis de } \\
\text { América Latina. Revista Eure, Vol. XXXIV, № 103, pp. 49-71, diciembre } 2008\end{array}$ \\
\hline \multirow{2}{*}{2009} & $\begin{array}{l}\text { Flores, Wormald, } \\
\text { Sabatini }\end{array}$ & $\begin{array}{l}\text { Segregación Residencial y trayectorias laborales de jefes de hogar en conjuntos de vivienda } \\
\text { social en Chile. Journal of Latin American Geography, Vol.6(1), pp.149-171, 2009 }\end{array}$ \\
\hline & $\begin{array}{c}\text { Garín, Salvo y } \\
\text { Bravo }\end{array}$ & $\begin{array}{l}\text { Segregación residencial y políticas de vivienda en Temuco. 1992-2002, Revista de Geografía } \\
\text { Norte Grande, 44: 113-128, } 2009\end{array}$ \\
\hline \multirow{2}{*}{2010} & Groisman y Suárez & $\begin{array}{l}\text { Segregación residencial e inserción laboral en el Conurbano Bonaerense. Población de Buenos } \\
\text { Aires. Año 7, número 11, abril de 2010, pp. 7-30, } 2010\end{array}$ \\
\hline & $\begin{array}{l}\text { Aliaga-Linares \& } \\
\text { Alvarez-Rivadulla }\end{array}$ & $\begin{array}{l}\text { Segregación residencial en Bogotá a través del tiempo y diferentes escalas. Lincoln Institute of } \\
\text { Land Policy, } 2010\end{array}$ \\
\hline \multirow{2}{*}{2011} & Perrén & $\begin{array}{l}\text { Segregación residencial socioeconómica en una ciudad de la Patagonia. Una aproximación al } \\
\text { caso de Neuquén, Estudios socio territoriales. Revista de Geografía, № 10, pp. 65-101, jul-dic } \\
2011\end{array}$ \\
\hline & Groisman & $\begin{array}{l}\text { Segregación residencial socioeconómica en Argentina durante la recuperación económica } \\
(2002-2007) \text {. Documentos de trabajo de Instituto de Estudios Latinoamericanos, DT, 03, } 2011\end{array}$ \\
\hline 2012 & Rodríguez Merkel & $\begin{array}{l}\text { El uso de zonas censales para medir la segregación residencial: contraindicaciones, propuesta } \\
\text { metodológica y un estudio de caso: Argentina, 1991-2001. FAHCE. VII Jornadas de Sociología } \\
\text { de la Universidad Nacional de La Plata "Argentina en el escenario latinoamericano actual: } \\
\text { debates desde las ciencias sociales". } 2012 \text {. }\end{array}$ \\
\hline \multirow{3}{*}{2013} & \multirow{2}{*}{ Molinatti } & $\begin{array}{l}\text { Segregación Residencial Socioeconómica en la ciudad de Córdoba (Argentina): Tendencias y } \\
\text { Patrones espaciales. Revista INVI, No. 79, noviembre 2013, Volumen No. 28, pp. 61-94, } 2013\end{array}$ \\
\hline & & $\begin{array}{l}\text { Segregación residencial e inserción laboral en el Córdoba. 2013. EURE. Vol. 39, No. 117, pp. } \\
\text { 117-145, mayo } 2013 .\end{array}$ \\
\hline & Sabatini y Wormald & $\begin{array}{l}\text { Segregación de la vivienda social: reducción de oportunidades, pérdida de cohesión, } \\
\text { Segregación de la vivienda social: ocho conjuntos en Santiago, Concepción y Talca, Colección } \\
\text { Estudios Urbanos UC, págs. 12-31, } 2013\end{array}$ \\
\hline \multirow{3}{*}{2014} & Elorza y Marengo & $\begin{array}{l}\text { Tendencias de la segregación residencial socioeconómica: El caso de Córdoba (Argentina) en } \\
\text { el periodo 2001-2008. 2014. Eure. Vol. 140. No.120. pp. 111-133, mayo } 2014\end{array}$ \\
\hline & $\begin{array}{l}\text { Gasparini, Cicowiez } \\
\text { y Sosa Escudero }\end{array}$ & $\begin{array}{l}\text { Pobreza y Desigualdad en América Latina: Conceptos, Herramientas y Aplicaciones. } \\
\text { Universidad Nacional de la Plata. Documento de Trabajo Nro. } 171 \text { octubre, } 2014\end{array}$ \\
\hline & Orellana y Osorio & Segregación socio-espacial urbana en Cuenca, Ecuador, Analítika, vol. 8, 27-38, 2014 \\
\hline \multirow{3}{*}{2016} & Elorza & $\begin{array}{l}\text { Segregación residencial socioeconómica y la política de vivienda social. El caso de la ciudad } \\
\text { Córdoba (Argentina) Cuaderno Urbano. Espacio, cultura, sociedad, vol. 20, núm. 20, pp. 71- 94, } \\
\text { junio, } 2016\end{array}$ \\
\hline & Rodríguez Merkel & $\begin{array}{l}\text { Desigualdades socioeconómicas y segregación residencial en dos décadas de signo político y } \\
\text { económico opuesto. La aglomeración Gran Buenos Aires entre } 1991 \text { y } 2010 \text {. CUADERNO } \\
\text { URBANO. Espacio, cultura, sociedad, vol. 21, núm. 21, pp. 5-28, noviembre 2016, } \\
\end{array}$ \\
\hline & $\begin{array}{l}\text { Moretti, Rojas y } \\
\quad \text { Peláez }\end{array}$ & $\begin{array}{l}\text { Segregación residencial socioeconómica y la política habitacional. Una aproximación a partir } \\
\text { del Programa "Mi casa, mi vida". Estudio de caso en la ciudad de Córdoba, Argentina. } \\
\text { Novedades en Población/ CEDEM, Año. 12. Vol. 23, pp.1-12, } 2016\end{array}$ \\
\hline
\end{tabular}

\begin{tabular}{|c|c|l|}
\hline \multicolumn{3}{|c|}{ Línea del tiempo México / Aportaciones conceptuales y teóricas } \\
\hline AÑo & AUTOR & TITULO DE ARTícULO \\
\hline 2001 & Cabrales, Canosa & $\begin{array}{l}\text { Segregación residencial y fragmentación urbana: los fraccionamientos cerrados en Guadalajara. } \\
\text { Espiral, vol. VII, núm. 20, enero/abril, pp. 223-253, 2001 }\end{array}$ \\
\hline 2003 & Duhau & $\begin{array}{l}\text { División social del espacio metropolitano y movilidad residencial, Papeles de Población, vol. 9, } \\
\text { núm. 36, abril-junio, pp. 161-210, 2003 }\end{array}$ \\
\hline 2004 & Cabrales & Latinoamérica: países abiertos, ciudades cerradas, Universidad de Guadalajara/Unesco, 2002 \\
\hline \multirow{2}{*}{2006} & $\begin{array}{c}\text { Caprón y González } \\
\text { Arellano }\end{array}$ & $\begin{array}{l}\text { Las escalas de la segregación y de la fragmentación Urbana, Trace. Travaux et Recherches dans } \\
\text { les Amériques du Centre, núm. 49, junio, PP. 65-75, 2006 }\end{array}$ \\
\cline { 2 - 3 } & Cabrales & $\begin{array}{l}\text { Tendencias recientes de las urbanizaciones cerradas y polarización social en Guadalajara, } \\
\text { Segregación social de espacio: Nuevos enfoques y patrones emergentes en México y Chile, } \\
\text { UNAM; Septiembre, 2006 }\end{array}$ \\
\hline
\end{tabular}


Marco A. M. Ortega

Laura B. Rodríguez
Cadernos Prolam/USP, v.16, n.31, p.160-188, jul./dez.2017

DOI: 10.11606/issn.1676-6288.prolam.2017.140636

\begin{tabular}{|c|c|l|}
\hline \multirow{2}{*}{2007} & Nuñéz Miranda & $\begin{array}{l}\text { Grandes desarrollos habitacionales en la Zona Conurbada de Guadalajara, Espiral, Estudios } \\
\text { sobre Estado y Sociedad, Vol. XIII No. 39, Mayo / agosto de 2007 }\end{array}$ \\
\hline \multirow{2}{*}{2008} & $\begin{array}{c}\text { Sandoval } \\
\text { Hernández }\end{array}$ & $\begin{array}{l}\text { Estudios sobre pobreza, marginación y desigualdad en Monterrey, CIEAP/UAEM, Papeles de } \\
\text { Población, No. 57, 2008 }\end{array}$ \\
\cline { 2 - 3 } 2009 & Salinas Arreortua & $\begin{array}{l}\text { Segregación residencial en la Zona Metropolitana de la Ciudad de México. X Coloquio } \\
\text { Internacional de Geocrítica, Universidad de Barcelona, Barcelona, 26 - 30 de mayo de 2008 }\end{array}$ \\
\cline { 2 - 4 } & Saraví & Transiciones vulnerables; Juventud, desigualdad y exclusión en México, CIESAS, 2009 \\
\hline \multirow{2}{*}{2011} & Castillo y Villar & $\begin{array}{l}\text { Segregación socio espacial en Cancún: 1990 - 2010 tres ciudades en una misma } \\
\text { Provincia, núm. 26, julio-diciembre, pp. 11-31, 2011 }\end{array}$ \\
\hline \multirow{2}{*}{2012} & Pérez Campuzano & $\begin{array}{l}\text { Segregación socio espacial urbana. Debates contemporáneos e implicaciones para las ciudades } \\
\text { mexicanas, Estudios Demográficos y Urbanos, vol. 26, núm. 2, mayo-agosto, pp. 403-432, 2011 }\end{array}$ \\
\cline { 2 - 3 } & $\begin{array}{c}\text { Rubalcava y } \\
\text { Schteingart }\end{array}$ & $\begin{array}{l}\text { Ciudades divididas. Desigualdad y segregación social en México. Primera edición ed. México: El } \\
\text { Colegio de México, 2012 }\end{array}$ \\
\cline { 2 - 3 } & Monkkonen & $\begin{array}{l}\text { La segregación residencial en el México urbano: niveles y patrones, EURE, vol 38 | no 114, pp. } \\
125-146, \text { mayo 2012 }\end{array}$ \\
\hline \multirow{2}{*}{2013} & Duhau & $\begin{array}{l}\text { La división social del espacio metropolitano. Una propuesta de análisis, Nueva Sociedad No 243, } \\
\text { enero-febrero de 2013 }\end{array}$ \\
\hline
\end{tabular}

\begin{tabular}{|c|c|c|}
\hline AÑo & AUTOR & TITULO DE ARTÍCULO \\
\hline 2000 & $\begin{array}{l}\text { Ruvalcaba y } \\
\text { Schteingart }\end{array}$ & $\begin{array}{l}\text { RUVALCABA, R. S. y Schteingart, M., 2000, "La división social del espacio en las grandes } \\
\text { metrópolis mexicanas. Un estudio comparativo", en El Mercado de Valores, año LX, núm. 4, abril }\end{array}$ \\
\hline 2001 & Schteingart & $\begin{array}{l}\text { RUVALCABA, R. S. y Schteingart, M., 2001, "Segregación socio espacial en el Área } \\
\text { Metropolitana de la Ciudad de México", en G. Garza (coord.), Atlas de la ciudad de México, } \\
\text { Gobierno del Distrito Federal/El Colegio de México, México. }\end{array}$ \\
\hline 2004 & $\begin{array}{l}\text { Aceves, De la Torre, } \\
\text { Safa }\end{array}$ &  \\
\hline \multirow{2}{*}{2005} & Venegas y Catañeda & $\begin{array}{l}\text { El crecimiento urbano y las características socioeconómicas de la Zona Metropolitana de } \\
\text { Guadalajara, la generación de áreas pauperizadas, Carta Económica Regional, Año 17, núm. 94, } \\
\text { octubre-diciembre } 2005\end{array}$ \\
\hline & González Hernández & $\begin{array}{l}\text { Segregación socio espacial, integración al mercado de trabajo y deterioro de los grupos de } \\
\text { ingreso medio en la zona conurbada Zacatecas-Guadalupe, México, } 2000 \\
\text { Papeles de Población, vol. 11, núm. 46, octubre-diciembre, pp. 79-108, } 2005\end{array}$ \\
\hline \multirow{2}{*}{2006} & Alegría & $\begin{array}{l}\text { Estructura Intraurbana y segregación social: El caso de Tijuana, Curso PUEC, UNAM, septiembre } \\
2016\end{array}$ \\
\hline & Fuentes y Cervera & $\begin{array}{l}\text { Mercados Inmobiliarios y sus efectos en la segregación espacial: el caso de Ciudad Juárez, } \\
\text { México, Estudios Fronterizos, Vol. 7, Núm.13, enero-junio, pp. 43-62, } 2006\end{array}$ \\
\hline 2007 & $\begin{array}{l}\text { González Arellano y } \\
\text { Villeneuve }\end{array}$ & $\begin{array}{l}\text { Transformaciones en el espacio socio residencial de Monterrey, 1990-2000, Estudios } \\
\text { Demográficos y Urbanos, vol. 22, núm. 1, enero-abril, pp. 143-178, 2007 }\end{array}$ \\
\hline \multirow{2}{*}{2008} & Saraví & $\begin{array}{l}\text { Mundos aislados: } \quad \text { segregación } \quad \text { urbana } \quad \text { y desigualdad } \\
\text { la ciudad de México, Revista Eure, Vol. XXXIV, N.․ 103, pp. 93-110, diciembre, } 2008\end{array}$ \\
\hline & Vilalta Perdomo & $\begin{array}{l}\text { Comentarios y mediciones sobre la segregación espacial en la Ciudad de México } \\
\text { Estudios Demográficos y Urbanos, vol. 23, núm. 2, mayo-agosto, pp. } 375-413,2008\end{array}$ \\
\hline \multirow{2}{*}{2009} & Baños Francia & $\begin{array}{l}\text { Segregación Residencial en el espacio turístico de Puerto Vallarta, Jalisco: 2001-2007, DCTS, } \\
\text { Universidad de Guadalajara, } 2009\end{array}$ \\
\hline & Ariza y Solís & $\begin{array}{l}\text { Dinámica socioeconómica y segregación espacial en tres áreas metropolitanas de México, } 1990 \text { y } \\
\text { 2000. Estudios Sociológicos, vol. XXVII, núm. 79, pp. 171-209, } 2009\end{array}$ \\
\hline \multirow{3}{*}{2010} & Schteingart & $\begin{array}{l}\text { División social del espacio y segregación en la ciudad de México. Continuidad y cambios en las } \\
\text { últimas décadas. En G. Garza y M. Schteingart, Los grandes problemas de México. II. Desarrollo } \\
\text { urbano y regional, pp. 345-387, México: El Colegio de México, } 2010\end{array}$ \\
\hline & $\begin{array}{l}\text { Pérez Campuzano y } \\
\text { Santos }\end{array}$ & $\begin{array}{l}\text { Segregación socio espacial en ciudades turísticas, el caso de Puerto Vallarta, México, Región y } \\
\text { sociedad, vol. XXII, no. 49. } 2010\end{array}$ \\
\hline & Pérez Campuzano & $\begin{array}{l}\text { Diferenciación socio espacial en la Zona Metropolitana de la Ciudad de México, Investigaciones } \\
\text { Geográficas, Boletín del Instituto de Geografía, UNAM, Núm. 74, pp. 92-106, } 2011\end{array}$ \\
\hline
\end{tabular}


Marco A. M. Ortega

Laura B. Rodríguez

\begin{tabular}{|c|c|c|}
\hline \multirow{3}{*}{2011} & González Arrellano & 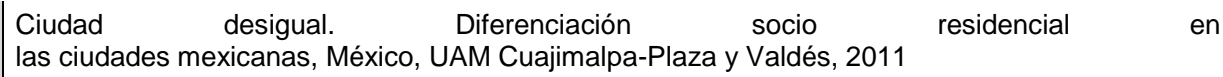 \\
\hline & Aguilar y Mateos & $\begin{array}{l}\text { Diferenciación sociodemográfica del espacio urbano de la Ciudad de México, EURE, vol. 37, no } \\
110 \text {, abril 2011, pp. 5-30, } 2011\end{array}$ \\
\hline & $\begin{array}{l}\text { Aparicio, Ortega y } \\
\text { Sandoval }\end{array}$ & $\begin{array}{l}\text { La segregación socio-espacial en Monterrey a lo largo de su proceso de metropolización, Región } \\
\text { y sociedad. año XXIII, no. 52, } 2011\end{array}$ \\
\hline \multirow{5}{*}{2012} & $\begin{array}{l}\text { Zamorano, Caprón y } \\
\text { González Arrellano }\end{array}$ & $\begin{array}{l}\text { Ser viejo en una metrópolis segregada; Adultos mayores en la ciudad de México, Nueva } \\
\text { Antropología, vol. XXV, núm. 76, enero-junio, pp. 83-102, } 2012\end{array}$ \\
\hline & Sánchez Peña & $\begin{array}{l}\text { Cambios en la Segregación socioeconómica en México. Realidad, Datos y Espacio. Revista } \\
\text { internacional de geografía y Estadística. Vol. } 3 \text { Núm. } 2 \text { mayo-agosto } 2012\end{array}$ \\
\hline & Peter Ward & $\begin{array}{l}\text { Segregación residencial: la importancia de las escalas y de los procesos informales de mercado, } \\
\text { Quid } 16, N^{\circ} 2,2012\end{array}$ \\
\hline & González Gómez & $\begin{array}{l}\text { Segregación urbana dirigida y segregación voluntaria: Querétaro, México, Ciudad, metrópoli y } \\
\text { mercado inmobiliario. Querétaro 1970-2010, UAQ-FCPyS, Acta de ponencia del XXX simposio de } \\
\text { la ICA; Viena, 2012. }\end{array}$ \\
\hline & Sánchez Peña & $\begin{array}{c}\text { ¿Viviendo cada vez más separados? Un análisis multigrupo de la segregación residencial en la } \\
\text { Ciudad de México, 1990-2005, Estudios Demográficos y Urbanos, vol. 27, núm. 1, enero-abril, pp. } \\
57-93,2012\end{array}$ \\
\hline \multirow{2}{*}{2013} & $\begin{array}{l}\text { Fuentes Flores y } \\
\text { Hernández }\end{array}$ & $\begin{array}{l}\text { Segregación socio espacial y accesibilidad al empleo en Ciudad Juárez, Chihuahua, Región y } \\
\text { sociedad, Año xxv, No. 56, } 2013\end{array}$ \\
\hline & Alvizo Carranza & La Colonia Obrera y la segregación urbana en Guadalajara, Historia 2.0, Año III, Número 6, 2013 \\
\hline 2017 & Domínguez Aguilar & $\begin{array}{l}\text { Las dimensiones espaciales de la segregación residencial en la ciudad de Mérida, Yucatán, A } \\
\text { principios del siglo XXI, Península vol. XII, núm. enero-junio, pp. 147-188, } 2017\end{array}$ \\
\hline
\end{tabular}

Recebido em 16/11/2017.

Aceito em 02/04/2018.

Publicado em 02/04/2018. 